\title{
Variability of Monsoon Low Level Jet and associated rainfall over India
}

5
Yesubabu Viswanadhapalli ${ }^{1 *}$, Hari Prasad Dasari ${ }^{2}$, Sanjeev Dwivedi ${ }^{1}$, Venkat Ratnam $\mathrm{M}^{1}$, Sabique Langodan ${ }^{2}$, and Ibrahim Hoteit ${ }^{2}$,

1. National Atmospheric Research Laboratory, Gadanki, Andhra Pradesh, India

2. King Abdullah University of Science and Technology, Physical Sciences and Engineering Division, Thuwal, Saudi Arabia

*Corresponding author: Yesubabu Viswanadhapalli, National Atmospheric Research Laboratory (NARL), Gadanki- 517112, Chittoor District, Andhra Pradesh, India. Email: yesubabu@narl.gov.in 
35 The structure and climatology of the monsoon low level jet (MLLJ) is studied based on dynamically downscaled simulations over a 37-year period (1980-2016) using the Weather

37 Research Forecasting (WRF) model. The simulations are conducted by adopting a continuous initialization method with daily re-initializations using ERA-Interim data as initial and boundary conditions. Validation of the downscaled fields with radiosonde data shows that the model has reasonable skill in reproducing MLLJ characteristics. Analysis of the simulations suggests that the MLLJ exhibits systematic diurnal variation: maximum winds of the synoptically induced

42 large-scale monsoon jet occur during the day-time, and the orographic channeled winds through 43 the mountains of East Africa, Hejaz, and Western Ghats in the night-time. These diurnal changes

44 in monsoon winds modulate the moisture convergence process and the associated evolution of 45 rainfall over India. Seasonal and monthly climatology of monsoon winds show that the model accurately reproduces the spatial pattern of winds and slightly overestimates ( 2 to $3 \mathrm{~m} / \mathrm{s}$ ) the

47 mean monthly winds over the Bay of Bengal and Arabian Seas. Analysis of wind variability and the trends using 37 years simulations suggest that the MLLJ exhibits an increasing trend in wind 49 speed on both seasonal and monthly scales, except for August which shows a decreasing trend.

50 The weakening of the MLLJ in August has a profound influence on the number of monsoon

51 depressions forming over the Bay of Bengal (which are decreasing), and on the number of break 52 days (which are increasing) and associated precipitation reduction over the central Indian region.

53 Keywords: Indian Summer Monsoon, Monsoon Low Level Jet, Dynamical Downscaling, 54 Monsoon Depression, and Rainfall. 
57

\section{Introduction}

The Indian summer monsoon (ISM) is an important component of the earth's climate system, involving complex interactions between the atmosphere, hydrosphere, and biosphere. The ISM alone brings $75-80 \%$ of India's annual precipitation from June to September (Jain and Kumar 2012). India is an agricultural country, and the ability to understand and forecast the monsoon systems (such as the onset, progression, and withdrawal of the ISM) has a profound influence on India's agricultural output, and consequently on its gross domestic product (GDP) (Gadgil 2006; Sabeerali et al. 2012). The major moisture component of the monsoon circulation results from the formation of the monsoon low level jet (MLLJ), which is also known as the Somali jet, or Findlater jet (Findlater 1969), over the western Arabian Sea.

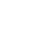

The MLLJ constitutes the strongest low-level cross-equatorial southwesterly wind-flow confined to a narrow region over the mountains of East Africa, it then turns anti-cyclonically and forms south-westerly winds off the Somali coast (at $\left.10^{\circ} \mathrm{N}\right)$. The MLLJ is formed primarily from the cross-equatorial flow induced by differential heating in the summer hemisphere (between the latitudes $20^{\circ} \mathrm{N}$ and $20^{\circ} \mathrm{S}$ ), which creates pressure gradient forces of heat lows over the Indian subcontinent and Mascarene High (Murakami 1976; Krishnamurti and Bhalme 1976; Hart 1977). MLLJ winds blow primarily at heights between 1000 and $4000 \mathrm{~m}$, with a core of jet at around $1500 \mathrm{~m}$ above mean sea level (Boos and Emanuel 2009), transport moisture from the southern to northern hemisphere (Cadet and Reverdin 1989; Roxy et al. 2017), and also control the formation and maintenance of monsoon inversion layers over the western central Arabian Sea (Sathiyamoorthy et al. 2013; Dwivedi et al. 2016). The MLLJ also plays a major role in modulating the amount of rainfall over the Indian subcontinent (Wu et al. 1999), in the activebreak monsoon rainfall spells, and intra-seasonal oscillations of the ISM (Sam and Murty 2002; 
80 Joseph and Sijikumar 2004). Apart from the MLLJ, the strong winds that funneled through

81 mountain valleys over east Africa region and eastern Arabian Peninsula have a profound

82 influence on the ISM and associated rainfall (Shown in Figure 1b). For instance, The passage of

83 warm, dry and dust-laden Shamal winds (from the east Arabian Peninsula), and Levar winds

84 (through mountains gaps in the southeast Iran) over the cold and moist monsoonal air mass

85 triggers the development of positive lapse rates and creates the thermal inversion layers over the

86 western Arabian Sea (Narayanan and Rao, 1989). The formation of the thermal inversion layers,

87 called monsoon inversion, play a major role in controlling the moisture budget in the lower and

88 mid-troposphere over the WAS, and also in transporting moisture towards the Indian

89 subcontinent (Narayanan and Rao, 1989; Dwivedi et al. 2016; Ramaswamy et al. 2017). The

90 monsoonal winds funneled through gaps of the east Africa region (ISM winds from the Tokar

91 gap) strongly constitute to the actual strength and spatial extent of MLLJ over the western

92 Arabian Sea. It was recently suggested that the branch of the monsoon winds channeling through

93 the gaps of east African mountains (Tokar and Afar) is a proxy to determine the strength of the

94 MLLJ (Bryan et al. 2019).

95 Several modelling studies have quantified different physical process associated with the

96 Somali jet and ISM, such as the role of the east African mountains, latent heating, and

97 strengthening and maintenance of the jet (e.g., Krishnamurti et al. 1976; Rodwell and Hoskins,

1995; Martin et al. 2013). Modeling efforts using the planetary boundary layer (PBL) model

99 (Krishnamurti et al. 1976, 1983) have successfully reproduced observed features of the Somali

100 jet, such as its curvature, peak intensity, and position. Many other numerical studies have

101 reported the significance of the Somali jet as a cross-equatorial moisture-flux feeding mechanism 
102 for the ISM and determined its role in creating convective instabilities required for triggering 103 heavy events over the west coast of India (Raymond 1978; Xavier 2018).

The inter-annual variability of monsoon winds and associated impact on ISM rainfall (ISMR) has been investigated in recent studies (Sandeep and Ajayamohan 2015; Aneesh and Sijikumar 2016; Roxy et al. 2017). Wang et al. (2013) reported a significant increasing trend in the northern hemispheric monsoon rainfall $\left(\sim 0.08 \mathrm{~mm} \mathrm{~d}^{-1}\right.$ per decade $)$ due to intensification of the Hadley and Walker circulations. The study shows that the hemispheric thermal contrast, which is related to increased meridional pressure gradients, enhances cross-equatorial flow from the northern to the southern hemisphere and results in increased moisture convergence and rainfall over the Asian monsoon regions. Aneesh and Sijikumar (2016) showed an increasing 112 trend for the MLLJ in July and September using three reanalysis datasets (NCEP2, ERAI, and 113 MERRA). Few studies (Rajendran et al. 2012; Krishnan et al. 2013) have proposed a weakening 114 mechanism for the monsoon circulation with respect to the increase in stability parameters over 115 the ISM region; however, the obtained results are not consistent with the increasing trend in 116 observed rainfall over central India (Goswami, 2006). Nevertheless, Sandeep and Ajayamohan 117 (2015) reported that the increased land-sea contrast over the ISM region results in a pole-ward 118 shift of the MLLJ, which in turn shifts associated rainfall over India. In addition, Krishnamurthy 119 and Ajayamohan (2010) suggested that monsoon trough strengthening and the low-level south120 westerly winds enhance moisture transport from the Arabian Sea towards the Indian 121 subcontinent, thereby providing positive feedback for intensifying rainfall over central India. 122 Furthermore, Roxy et al. (2017) reported a threefold increase in the number of extreme 123 precipitation events over central India which is significantly related to the changes in MLLJ over 124 the Arabian Sea. Their study also quantified the contribution of moisture content to these 
125 extreme events and their results indicate that about 36\% from the Arabian Sea, $26 \%$ from the 126 Bay of Bengal and 9\% from the central Indian Ocean. This moisture contribution from Indian 127 seas is mainly through the MLLJ due to the northwestward propagation of the monsoon 128 depressions (Sandeep and Ajaymohan, 2015). High-resolution dynamical downscaling using the regional climate models (RCMs) has 130 facilitated many researchers to conduct a detailed analysis of various physical processes (Giorgi 131 and Mearns, 1991) and has been utilized in many climate impact studies to reproduce regional 132 climatic features (e.g., Giorgi, 2006; Hari Prasad et al. 2014; Pattnayak et al. 2013; Srinivas et al. 133 2013, 2015; Raju et al. 2014; 2015). However, as the RCMs are primarily driven by initial and 134 boundary conditions from global fields, systematic errors present in the global model often 135 amplify after downscaling at regional scale (Rojas and Seth, 2003; Viswanadhapalli et al. 2017).

136 Chen et al. (2018) conducted seasonal simulations of the ISM using the cloud-permitting 137 Weather Research and Forecasting (WRF) model for a period of five years (2007 to 2011) and 138 reported that systematic errors are reduced when simulating the monsoon intra-seasonal 139 oscillations at regional scale. However, the results of this study also indicated significant 140 quantitative model biases in the downscaled fields which were attributed to the continuous 141 integration of the RCM on a seasonal scale. To minimize the influence of these systematic model 142 errors, and to retain the knowledge of the sequence of weather events in the climate flow field 143 (Lucas-Picher et al. 2013), many researchers have employed the dynamic downscaling technique 144 with continuous re-initializations in climate downscaling studies (e.g., Lo et al. 2008; Jiang et al. 145 2009; Lucas-Picher et al. 2013; Viswanadhapalli et al. 2017; Hima Bindu et al. 2018; Dasari et 146 al. 2019). 
Based on the continuous re-initialization simulations with WRF model, the objective of

148

149

150

151

152

153

154 155

156

157

158

159

160

161

162

this study is to first evaluate the skill of the downscaled fields in re-producing the regional climatology of the MLLJ and its variability during 1980 and 2016. We then provided the evidence that the decreasing trend in the number of monsoon depressions forming in August over the Bay of Bengal due to the decrease tendency in wind strength of the MLLJ and explain its mechanism. The study is structured as follows. Section 2 describes the model design, experimental setup, and observational datasets; Section 3 presents the validation of the downscaled simulations based on the gridded reanalysis datasets and radiosonde observations, and followed by the analysis of spatial and temporal variability of MLLJ. Section 4 summarizes the main results of this study and offers concluding remarks.

\section{Data and methodology}

The Advanced Research core of WRF (WRF-ARW) version 3.9.1 was configured with a model domain of $18 \mathrm{~km}$ horizontal resolution, and 53 vertical levels. The model domain covered the ISM region between longitudes and latitudes of $26^{\circ} \mathrm{E}-115^{\circ} \mathrm{E}$ and $23^{\circ} \mathrm{S}-47^{\circ} \mathrm{N}$, respectively (Figure 1). Terrain elevation, land use, land cover, and soil information over the model domain were obtained from the arc 5-min $(\sim 10 \mathrm{~km})$ resolution USGS data.

A combination of the following physical parameterization schemes was used: Thompson et al. (2008) for the cloud microphysical process; Mellor-Yamada-Nakanishi-Niino level 2.5 (Nakanishi and Niino, 2004) closure for PBL turbulence; Betts-Miller-Janjic for cumulus convection (Janjic, 1994); NOAH MP scheme for the land surface processes (Niu, 2011); and the RRTMG radiation scheme (Iacono et al. 2008) for both longwave and shortwave radiation processes. These model physics configurations were adopted after considering several Monsoon studies conducted with WRF (Mukhopadhyay et al. 2010; Rajeevan et al. 2010; Srinivas et al. 
170 2013, 2015, 2018; Samala et. al. 2013; Raju et al. 2015; Attada et al. 2018). Simulations were

171 conducted using a consecutive re-initialization method with initialization on a daily basis at 1200

172 UTC, and the model was integrated for 36-h using ECMWF ERAI data (Dee et al. 2011) as

173 initial and boundary conditions. On every daily-initialization cycle, the model was configured to

174 generate hourly outputs over the 36-hours simulation time. The first 12-hour outputs from each

175 simulation are discarded as spin-up and the remaining 24 hour outputs are merged to generate a 176 comprehensive climate dataset over the 37-year period.

178 Research and Applications version-2 (MERRA2) obtained from the Global Modeling and 179 Assimilation Office, NASA (Gelaro et al. 2017) at lower tropospheric levels (925, 900, 850, and $180700 \mathrm{hPa}$. WRF surface winds are further compared to the Cross-Calibrated Multi-Platform 181 (CCMP) multi satellite surface wind analysis, version-2 (Atlas, 2011), and the performance of 182 downscaled profiles is evaluated using the quality controlled instantaneous radiosonde data 183 obtained from the NOAA Integrated Global Radiosonde Archive (IGRA).The twice daily 184 temperature, humidity and wind profiles (at 0000 UTC and 1200 UTC) extracted from the 185 nearest model grid points to the observed locations are considered to compute the statistical 186 scores against the radiosonde data over the 37 -year simulation period. The downscaled rainfall is 187 compared with the TRMM 3B42V7 satellite merged rainfall product (Huffman et al. 2007) 188 obtained at 3-hourly intervals from ftp://trmmopen.gsfc.nasa.gov/pub/merged. The model 189 comparisons are performed using 6-hourly precipitation estimates ( $\mathrm{mm} / \mathrm{h})$ of TRMM s which we 190 prepared by combining adjacent 3 hourly of TRMM data (i.e, mean of TRMM 3-hourly rainfall $191(\mathrm{~mm} / \mathrm{h})$ at 0000UTC and 0300 UTC used as 0000 UTC TRMM 6-hourly rainfall). 


\section{Results and Discussion}

In this section, 37 years downscaled data for the ISM period (June to September, JJAS) are validated with IGRA radiosonde data. Further, the climatology of the MLLJ, its vertical and horizontal extensions, and its influence on ISM rainfall are analyzed. The trends in MLLJ strength and their impact on rainfall over the Indian subcontinent are then investigated.

\subsection{Validation of downscaled ISM dataset}

To understand model errors associated with resolving the MLLJ, five radiosonde stations namely Minicoy $\left(8.3^{\circ} \mathrm{N}, 73.15^{\circ} \mathrm{E}\right)$, Salalah $\left(17.03^{\circ} \mathrm{N}, 54.08^{\circ} \mathrm{E}\right)$, Mumbai $\left(19.11^{\circ} \mathrm{N}, 72.85^{\circ} \mathrm{E}\right)$, Thiruvananthapuram $\left(8.43^{\circ} \mathrm{N}, 76.95^{\circ} \mathrm{E}\right)$, and Chennai $\left(13.0^{\circ} \mathrm{N}, 80.18^{\circ} \mathrm{E}\right)$ were selected to compute statistical scores (such as bias and RMSE) between the model simulations and observations from surface to 5-km height above ground level (AGL) for different atmospheric variables (Figure 2). The temperature RMSE is minimum, around $1^{\circ} \mathrm{C}$ at the surface for Thiruvananthapuram, Chennai, and Minicoy stations (Figure 2a) which is, but increases to $1.75^{\circ} \mathrm{C}$ for heights between $1 \mathrm{~km}$ and $2 \mathrm{~km}$. The bias values vary between $-1{ }^{\circ} \mathrm{C}$ and $0.5^{\circ} \mathrm{C}$ between the surface and $2.5 \mathrm{~km}$ AGL. Radiosonde stations located near the core of the MLLJ (Salalah, Mumbai, Thiruvananthapuram and Minicoy) shows a moderately high bias $\left(>-1.5^{\circ} \mathrm{C}\right)$ and $\operatorname{RMSE}\left(>1.5^{\circ} \mathrm{C}\right)$ from the surface to 2-km AGL. The RMSE of $\mathrm{RH}$ at three stations (Thiruvananthapuram, Chennai, and Minicoy) is about $8 \%$ in lower levels and increases up to $15 \%$ in the upper levels $(2-3 \mathrm{~km})$. The bias values of mean bias at these stations also suggest that the model exhibits a moist bias at lower levels and a dry bias at upper levels $(1.5$ and $2.5 \mathrm{~km}$, Figure $2 \mathrm{f}$ to $2 \mathrm{j}$ ). Though the $\mathrm{RH}$ errors at Salalah have similar pattern as the other four stations, they show the maximum values and slightly (moist bias) shifted toward the lower levels. The 
214 RMSE of the wind speed is about 2-3 $\mathrm{m} \mathrm{s}^{-1}$ in the upper levels and is maximum (between 3 to 3.5

$215 \mathrm{~m} \mathrm{~s}^{-1}$ ) in the lower levels. The RMSE and bias obtained from the comparison of the temperature 216 and $\mathrm{RH}$ profiles suggests a strong relation with the corresponding errors in zonal and meridional

217 winds. The day-height section of 37-year mean daily RMSE and bias computed with radiosonde 218 data for the different variables at Minicoy station (Figure 3). The RMSE values and bias are 219 computed by selecting instantaneous radiosonde data and respective model parameters (both 2200000 UTC and 1200 UTC) for each day of the year (1 to 365 days) over the 37-year period (74 221 values on a day), and the averages of 74 twice-daily means values are presented in Figure 3 . The 222 daily mean RMSE and bias values plotted against the model height reveals a bias in wind speed 223 around $2 \mathrm{~m} \mathrm{~s}^{-1}$, and RMSE of about $3 \mathrm{~m} \mathrm{~s}^{-1}$ over the core region of the MLLJ (over Salalah from 2240.5 to $2-\mathrm{km}$ ) from the month of June to September. These errors indicate that the model 225 reproduced reasonably well the height and temporal variability of the MLLJ and the errors in the 226 simulated wind speed mainly aroused from the meridional component. For temperature and 227 relative humidity, bias and RMSE during the JJAS period associated with MLLJ (1 to 3-km) are 228 approximately $-1{ }^{\circ} \mathrm{C}$ and $2{ }^{\circ} \mathrm{C}$, and $-10 \%$ and $20 \%$ respectively. Hima Bindu et al. (2018) has 229 validated the same downscaled simulations of WRF model at different heights using the 230 radiosonde observations over a tropical station 'Gadanki' $\left(13.5^{\circ} \mathrm{N}\right.$ and $\left.79.2^{\circ} \mathrm{E}\right)$, and reported that 231 the WRF model exhibits very good skill for wind and temperature from surface to 13-km (RMSE 232 of 1 to $2 \mathrm{~m} \mathrm{~s}^{-1}$ for winds and 0.5 to $1{ }^{\circ} \mathrm{C}$ for temperature). Their results also indicate that the 233 model skill found to be slightly variable (RMSE of 2 to $3 \mathrm{~m} \mathrm{~s}^{-1}$ ) with the radiosonde observations 234 in the jet regions of easterly and westerlies (from 13 to 18-km AGL) during ISM season and 235 winter months, respectively. The results of these comparisons between the model and 
236 observations suggest that WRF exhibits a reasonable high skill in reproducing the MLLJ 237 characteristics.

\subsection{Diurnal evolution of MLLJ}

Previous studies have emphasized the need for high spatial-temporal resolution data for analysis of the diurnal cycle of monsoon (Roja Raman et al. 2011). In this respect, the availability of high resolution downscaled WRF winds enables to study the diurnal evolution of low-level winds. The spatial distribution of $925 \mathrm{hPa}$ winds during different times of the JJAS season $(0000,0600,1200$, and 1800 UTC shown in Figure 4) clearly outlines the large diurnal variation of the MLLJ. The speed at the core of MLLJ ( $\left.>22 \mathrm{~m} \mathrm{~s}^{-1}\right)$ does not change significantly in magnitude between the hours; but there is a change in the spatial extent of MLLJ winds. A longitudinal-pressure section of horizontal winds (Shown in Figure S1) reveal, however, that the spatial extent of the MLLJ core is high during 0600 UTC and 0000 UTC, with maximum wind speeds $\left(>24 \mathrm{~m} \mathrm{~s}^{-1}\right.$ ) extending both vertically (from 950 to $850 \mathrm{hPa}$ ) and horizontally over a large region of the western Arabian Sea (Figure $4 a$ and $b$ ). The spatial and vertical extent of MLLJ core is reduced significantly during 1800 UTC and confined to a smaller region, also the magnitude of MLLJ core reduced to around 20-21 $\mathrm{m} \mathrm{s}^{-1}$ and the core of MLLJ shifted to lower

252 heights (950 -900 hPa) during the evening hours (1800 UTC). The strong winds over the Tokar 253 (Tokar jet over Sudan), Shamal jet (eastern part of Iran), westerly winds over eastern part of Maharashtra and Andhra Pradesh are found maximum at 0000 UTC, while the westerly winds 255 over the leeward side of Kerala, Tamilnadu and Sri Lanka peak at 1800 UTC (Figure S2). A 256 similar analysis (Figure S3) was conducted for the winds at $850 \mathrm{hPa}$, and results suggest that the 257 diurnal variability of winds at the mountain gaps is stronger at lower levels (925 hPa). The 258 development of a nocturnal low-level jet (LLJ) through the valleys over the Western Ghats could 
259 be the major driver for the maximum winds occurring at 1800 UTC. Prabha et al. (2011) argued 260 that the nocturnal jet, which is induced over the eastern parts of the Western Ghats, possibly 261 develops due to the baroclinicity of the valley environment; it is then amplified during the night 262 hours as a result of thermal wind phenomena that has different characteristics from the large263 scale MLLJ of monsoon origin. Nair et al. (2015) also reported systematic diurnal variation in 264 the MLLJ, with a maximum jet speed at lower altitudes during midnight hours and a minimum 265 wind speed and maximum height during evening hours using radiosonde observations. In this 266 study, the analysis of simulated ISM winds at different heights (Figure S4) confirms the findings 267 by Nair et al. (2015); the MLLJ flowing through the Western Ghats does exhibit systematic 268 diurnal variation. The vertical extent of the MLLJ is maximum during evening hours (1800 269 UTC) and reaches up to $750 \mathrm{hPa}$ over the Indian peninsular, with wind speed of around $16 \mathrm{~m} \mathrm{~s}^{-1}$. 270 The MLLJ reaches maximum speed of around $18 \mathrm{~m} \mathrm{~s}^{-1}$ in the morning hours, with core speeds 271 confined to lower heights between 950 and $900 \mathrm{hPa}$.

To further understand the diurnal evolution of the MLLJ winds, radiosonde winds at 0000 273 UTC and 1200 UTC over a 37-year period were analyzed from data recorded at Minicoy station $274\left(8.30^{\circ} \mathrm{N}, 73.15^{\circ} \mathrm{E}\right)$, which is located near the core region of the MLLJ and the Western Ghats. 275 The time-height section of wind speeds from radiosonde and the corresponding WRF 276 downscaled values are presented in Figure 5. The observations and model simulations confirm 277 that the height of the MLLJ reaches up to $4 \mathrm{~km}$, with vertical extension of isotachs seen at 1200 278 UTC (evening hours). Though the model pattern of isotachs matched with radiosonde, significant 279 variations are not seen in the simulated height and strength of MLLJ core at both times $(0000$ 280 UTC and 1200 UTC). There is, however, a clear increase (by $2 \mathrm{~m} \mathrm{~s}^{-1}$ ) in the observed winds of 281 radiosonde from 0000 UTC to 1200 UTC during the months of June and July. 
An analysis of the diurnal variations of MLLJ during the individual monsoon months

283

284

285

286

287

288

289

290

291

292

293

294

295

296

297

298

299

300

301

302

(Figure S5) indicates that the strength of the MLLJ is higher and exhibits larger diurnal variations during the peak monsoon months of July and August than in June and September. The influence of the pressure gradient and the resulting large-scale southwesterly flow is stronger during the day time, while the effect of mountain gaps is predominant during night time where the secondary flow of the MLLJ winds is found to be stronger (Ruchith et al. 2014; Du et al. 2015). The diurnal changes in the winds can alter the humidity gradients in the LLJ outflow region, which then triggers moisture convergence and favors the formation of convection systems (Chen and Tomassini, 2015). The analysis of 6-h rainfall (mm/h) from TRMM and WRF suggest that rainfall over the Indian region (Figure 6) exhibits high spatial variability, with maximum day-time rainfall over the windward side of the Western Ghats and night-time rainfall over the central and peninsular India. A similar analysis of peak rainfall over the central Indian region during the night to early morning hours has been reported in previous studies (Basu, 2007; Deshpande and Goswami, 2014). Therefore, diurnal changes in the strength and position of the MLLJ play a significant role in the evolution of diurnal monsoonal rainfall over India from June to September. Though the spatial patterns of WRF rainfall are in close agreement with TRMM, the magnitude of rainfall is overestimated (1 to $2 \mathrm{~mm} / \mathrm{h}$ ) over the Western Ghats, central India and west coast of Myanmar. This can be attributed to the tendency of the WRF model to simulate enhanced pressure gradients between the heat low and mascarene high, which leads to the overestimation of the monsoon winds and associated rainfall (Srinivas et al. 2013).

\subsection{Structure and climatology of MLLJ}

The validation of downscaled fields with radiosonde data at five stations may not well infer the skill of the model in capturing the seasonal flow pattern of ISM. A seasonal scale comparison of 
305 downscaled fields with an independent product of comparable resolution may indeed provide

more confidence in the downscaling capability of WRF. Before analyzing the intra-seasonal variability and trends in monsoon winds during JJAS months, we further compared JJAS winds from WRF against the MERRA2 analysis to illustrate that the downscaled mean JJAS winds accurately capture the seasonal pattern.

\subsubsection{Seasonal analysis of MLLJ}

Figure 7 presents the 37-year climatology of ISM winds (averaged from June to September) at $850 \mathrm{hPa}$ (Figure 7a and b), $925 \mathrm{hPa}$ (Figure 7c and d), and (Figure 7e and f) from CCMP, MERRA2, and WRF. The WRF mean flow patterns of ISM winds (such as the crossequatorial flow associated with south-easterlies at the south of the equator and the strong southwesterlies in the north of the equator with core maximum winds $\left(>18 \mathrm{~m} \mathrm{~s}^{-1}\right)$ lie between the regions of $8^{\circ} \mathrm{N}$ to $15^{\circ} \mathrm{N}$ and $50^{\circ} \mathrm{E}$ to $60^{\circ} \mathrm{E}$ and are in good agreement with the reanalyzed datasets. The core region of the jet (MLLJ) extends vertically up to $850 \mathrm{hPa}$ in both MERRA2 and WRF and is the backbone for the ISMR as it transports moisture from the Indian Ocean to the land masses of India (Krishnamurti et al. 1976; Krishnamurti et al. 1983). The amount of moisture transported to the Indian land mass is mainly associated with the strength, position, and vertical structure of the MLLJ (Sandeep and Ajaymohan, 2015). The position of the MLLJ in both MERRA2 and WRF is elongated in a southwest to northeast direction (starting from the equator to around $18^{\circ} \mathrm{N}$ at $10 \mathrm{~m}$ and $925 \mathrm{hPa}$ ) and entering over the west coast of India. At 850 $\mathrm{hPa}$, the MLLJ becomes more parallel to the equator and its core is located at around $8^{\circ} \mathrm{N}-12^{\circ}$ $\mathrm{N}, 55^{\circ} \mathrm{E}-60^{\circ} \mathrm{E}$ (mainly westerly), which suggests that its position as well as its vertical and horizontal structure from the surface to the lower troposphere, are not uniform. These results are 
327 consistent with those of the 35-year (1980-2014) mean wind-flow pattern obtained from 328 MERRA version-1, as reported in recent studies (Aneesh and Sijikumar, 2016). the orographically channeled winds of an ISM origin (Viswanadhapalli, et al. 2017) over the Red Sea, which passes through mountain gaps in east Africa and on the western Arabian Peninsula. There is a slight underestimation $\left(0.5\right.$ to $\left.1 \mathrm{~m} \mathrm{~s}^{-1}\right)$ in WRF downscaled cross-equatorial flow over the southern Indian Ocean and Shamal jet over Arabian Gulf compared to MERRA2 and CCMP datasets. A slight overestimation of simulated winds $\left(1 \mathrm{~m} \mathrm{~s}^{-1}\right)$ is also noticed over the BOB and Arabian Seas and also of orographically driven winds over the Gulf of Aden. This can be attributed to the tendency of the WRF model to simulate a stronger Tibetan anticyclone, which results in an increased pressure gradient between the Indian Subcontinent and Madagascan regions (Srinivas et al. 2013).

To characterize the spatial and vertical extensions of the MLLJ in both the north-south and east-west directions, we analyzed the height-section of winds averaged over latitudinal $\left(5^{\circ}\right.$ $\left.\mathrm{N}-20^{\circ} \mathrm{N}\right)$ and longitudinal $\left(50^{\circ} \mathrm{E}-60^{\circ} \mathrm{E}\right.$ and $\left.84^{\circ} \mathrm{E}-94^{\circ} \mathrm{E}\right)$ regions of the MLLJ from MERRA2 and the WRF fields (Figure 8) for the JJAS season. The height-longitude section of wind speeds

343 (Figure 8a and $\mathrm{b}$ ) averaged over $5^{\circ} \mathrm{N}-20^{\circ} \mathrm{N}$ from MERRA2 shows that the core of the MLLJ $(<$ $34415 \mathrm{~m} \mathrm{~s}^{-1}$ ) is located at around $50^{\circ} \mathrm{E}-60^{\circ} \mathrm{E}$ and that it is vertically extended up to $800 \mathrm{hPa}$ (with a maximum at around $925 \mathrm{hPa}$ ). Although similar wind patterns are noticed from the WRF, the 346 core regions of the WRF MLLJ $\left(>15 \mathrm{~m} \mathrm{~s}^{-1}\right)$ are extended in both vertical and horizontal 347 directions than MEERA2. In addition, the height of the simulated maximum of the MLLJ is also 348 larger than with MERRA2. Similarly, the height-latitude section of wind speeds averaged over $50^{\circ} \mathrm{E}-60^{\circ} \mathrm{E}$ (Arabian Sea) from both MERRA2 and the WRF (Figure 8c and d) shows two cells 
350 located to the south (around $10^{\circ} \mathrm{S}-15^{\circ} \mathrm{S}$ ) and north of the equator (around $10^{\circ} \mathrm{N}-15^{\circ} \mathrm{N}$ ). The 351 northern cell of the MLLJ is extended up to $700 \mathrm{hPa}$ with a maxima located at around $900 \mathrm{hPa}$ in 352 MERRA2, but MLLJ core is slightly located higher extended (from $900 \mathrm{hPa}$ to $850 \mathrm{hPa}$ ) 353 vertically in WRF compared to MERRA2 (from $925 \mathrm{hPa}$ to $875 \mathrm{hPa}$ ). In addition, the strength of 354 the downscaled MLLJ with the WRF is relatively higher than that of MERRA2. Although the 355 height-section of wind speeds averaged over $84^{\circ} \mathrm{E}-94^{\circ} \mathrm{E}$ (i.e., BOB) from both MERRA2 and the 356 model (Figure 8e and f) shows two cells located south (at around $10^{\circ} \mathrm{S}-15^{\circ} \mathrm{S}$ ) and north of the 357 equator (around $\left.10^{\circ} \mathrm{N}-15^{\circ} \mathrm{N}\right)$, the jet intensities in $\mathrm{BOB}$ are weak $(<11 \mathrm{~m} / \mathrm{s})$ compared to the Arabian Sea. The analysis conducted here clearly suggests that the core region of the MLLJ is 359 located at around $10^{\circ} \mathrm{N}-15^{\circ} \mathrm{N}$ and $50^{\circ} \mathrm{E}-60^{\circ} \mathrm{E}$ and that it is extended vertically up to $700 \mathrm{hPa}$ 360 with maximum core winds persisting at around $900 \mathrm{hPa}$.

\subsubsection{Variability of MLLJ during EI Niño and La Nina years} and 2015), moderate to week (1986, 1994, 2002, 2004, 2006, 2009, and 2014) El Niño years as well as the strong $(1988,1998,1999,2007$, and 2010) and moderate to week $(1983,1984,1995$, 2005, 2008, 2011, 2016) La- Niña years are analyzed from WRF and MEERA2 data. The results of the mean seasonal winds and their difference (La-Nina - El-Nina) from moderate to week ENSO years (Figure S6) do not differ much from the normal years. However, the differences in

368 the mean seasonal winds are significant during strongest La- Niña and El-Niño years. So, we 369 presented the results of wind pattern during the strongest ENSO years (Figure 9) which reveal 370 that the spatial extent and core wind velocity of LLJ is higher during the La- Niña years 371 compared to El-Nino years over Arabian Sea and also the stronger winds up to 2 to $3 \mathrm{~m} / \mathrm{s}$ seen 372 through mountain gaps over Red Sea and Gulf of Aden. However, the contrast feature found 
373 with 850-winds over Peninsular India and BOB with stronger winds are seen in El-Nino years 374 when compared to La-Nino years. In addition, though the similar features are noticed in both 375 WRF and MERRA2 data, the downscaled winds of WRF exhibit increased wind speeds by $1 \mathrm{~m} / \mathrm{s}$ 376 and the extent of MLLJ is large compared to MERRA during El-Nino years. Also there is a clear 377 enhancement in the cross-equatorial flow $(1 \mathrm{~m} / \mathrm{s})$ in the downscale simulations during La- Niña 378 years. The latitudinal (from 5 to $20^{\circ} \mathrm{N}$ ) average JJAS winds between the longitude from $55^{\circ} \mathrm{E}$ to $37960^{\circ} \mathrm{E}$ from WRF (Shown in Figure S7) suggests that the prevalence of strong winds are 380 observed during the La- Niña, particularly the vertical and longitudinal extent of the MLLJ core 381 during La- Niña years is high over AS. Moreover, African Easterly Jet (600 hPa) and Shamal jet from the top $\left(600 \mathrm{hPa}\right.$ to $500 \mathrm{hPa}$ ) with core around $550 \mathrm{hPa}$ near $40{ }^{\circ} \mathrm{E}$ is observed to be strong during La- Niña years. However, the vertical extent of the westerly winds (up to $650 \mathrm{hPa}$ ) over peninsular India and BOB (between $80^{\circ} \mathrm{E}-95^{\circ} \mathrm{E}$ ) exhibit higher winds (by 2 to $3 \mathrm{~m} / \mathrm{s}$ ) during ElNino while westerly winds confined at lower levels $750 \mathrm{hPa}$ during La-Nino with the strength of winds found to be less. Although the variability of MLLJ during El Niño and La Niña years was extensively investigated, our results reveal an intensification of the westerly winds in terms of magnitude and an enhancement of their vertical extent over the India Peninsula and the Bay of Bengal regions during El Niño years. We also noticed an increased channeled flow through the mountain gaps of the East-African and Western Ghats of India during La Niña years.

\subsubsection{Analysis of MLLJ on sub-seasonal scale}



significantly decreases in September. The mean position of the MLLJ shifts from $12^{\circ} \mathrm{N}$ to $13^{\circ} \mathrm{N}$ latitude and its width increases during July and August; this is attributed to the increased pressure gradient between the Indian sub-continent and the Madagascar regions, and also partly to the rise in the mountain gaps winds through the east-African mountains ranges and the winds over the Red Sea region (Tucker and Pedgley, 1977; Viste and Sorteberg, 2013; Viswanadhapalli et al. 2017). The difference between MERRA and WRF outputs (shown in left panels of Figure 10) clearly demonstrates the added value of the downscaled fields with a difference of nearly 2 to $3 \mathrm{~m} / \mathrm{s}$ in the mountain gaps of the Gulf of Aden and over the Bay of Bengal. The impact of downscaling is also significant in the case of channeled wind flow over the East-African mountains and Western Ghats regions of India. The increased channeled flow in the downscaled fields is one of the contributing factors for the increase in the spatial extent of MLLJ over western Arabian Sea. A comparison between WRF and MERRA for the peak months (July and August) reveals that the mean flow pattern and position of MLLJ are well simulated by the WRF model, although the major differences (up to $3 \mathrm{~m} \mathrm{~s}^{-1}$ ) in their intensities noticed over the eastern Arabian Sea and BOB. Monthly variations in the vertical extent of MLLJ winds are plotted in the height-longitude section at $10^{\circ} \mathrm{N}$, as shown in Figure 11. The longitudinal section of the winds suggests that the strength and width of the MLLJ (both vertically and horizontally) are increased from June to July; further MLLJ started reducing its strength and width in the month of August and subsequently reduced to its minimum strength and extension in September. The latitudinalheight cross-section plotted at $13^{\circ} \mathrm{N}$ (Figure S8) further confirms that the winds are at their maximum strength during July and August, possibly due to the merging of orographically driven winds from the Red Sea with those of the Somali jet.

\subsection{Interannual variability of MLLJ}


The strength of the MLLJ was analyzed at different levels to study the long-term variability during the ISM. The time series of the MLLJ and winds averaged over $10^{\circ} \mathrm{N}-15^{\circ} \mathrm{N}$ and $50^{\circ} \mathrm{E}-60^{\circ} \mathrm{E}$ at four different heights $(925,900,850$, and $700 \mathrm{hPa}$ levels) from MERRA and

422 the WRF model clearly show (Figure 12) a significant increasing trend in the strength of the winds at all analyzed levels. Mean seasonal surface temperature (shown in Figure S9) shows 424 significant increasing trends in temperature from Central India to Pakistan. These changes 425 leading an increase in the land-sea temperature contrast and associated changes in the surface 426 pressures (Figure not shown), between the heat-low over the Indian subcontinent and high 427 pressure over Madagascar, are the possible reasons in increasing trends in the MLLJ (at 850 $\mathrm{hPa}$ ). The results of this study also reveal that the magnitude of increasing trend in MLLJ is relatively lower at $925 \mathrm{hPa}$ and higher at $850 \mathrm{hPa}$, compared to the other levels $(700$ and 900 $\mathrm{hPa}$ ). Although the WRF model reproduces similar trends to those observed in MERRA data, the 431 strength of the winds is slightly overestimated by about $0.5 \mathrm{~m} \mathrm{~s}^{-1}$ at lower levels $(900 \mathrm{hPa}$ and $925 \mathrm{hPa}$ ), as reported in the previous section. The model therefore reproduces the observed trend with almost the same strength as that of MERRA2 at higher levels $(850 \mathrm{hPa})$ but it slightly overestimates at lower levels, and significantly overestimates at higher levels (700 hPa); this is probably related to the model simulated pressure gradients being higher at lower levels, thereby 436 resulting in a slight overestimation of winds. (averaged over $10^{\circ} \mathrm{N}-15^{\circ} \mathrm{N}$ and $50^{\circ} \mathrm{E}-60^{\circ} \mathrm{E}$ ) was plotted from MERRA and WRF at $925 \mathrm{hPa}$ 439 and $850 \mathrm{hPa}$ levels for individual months. The results presented in Figure 13 suggest that the trend pattern for the MLLJ is essentially similar at both 925 and $850 \mathrm{hPa}$ for all four months. However, there is a clear positive or increasing trend in the MLLJ in June, July, and September, 
442 and a significant declining trend in August, which suggests the strong sub-seasonal variability of

443 MLLJ winds. The geopotenital height at 850-hPa in August indicate (Figure S10) a decreasing 444 trends in geopotenital (where the increasing trends in temperatures) over central to northern 445 Arabian Peninsula, resulting the decreasing strength of Arabian Anti cyclone may be the one of 446 possible factor for the weakening of MLLJ (at $850 \mathrm{hPa}$ ). This declining trend of the MLLJ in 447 August influences the progression of the monsoon and the transport of moisture towards the 448 Indian landmass and associated ISMR (Joseph and Sijikumar, 2004). Previous studies (Pattnayak 449 et al. 2016; Aneesh and Sijikumar, 2016) reported that the weaker convection over BOB and 450 increased surface pressure over the heat-low region can lead to a decrease in the strength of the MLLJ in August and subsequent intensification of the heat-low over Pakistan in September.

452 These changes in the monsoon circulation are likely reasons behind the increasing trends of 453 MLLJ in September. Although the ISM season extends basically from June to September, the 454 active phase of the ISM is confined to July and August (Aneesh and Sijikumar, 2016).

\subsection{The impact of the MLLJ variability on ISM Rainfall}

To study the influence of MLLJ winds on ISMR, we compute the correlations between the mean seasonal MLLJ (at $850 \mathrm{hPa}$ ) from MERRA and WRF with the observed mean seasonal ISMR (Figure 14). We chose 850-hPa winds to check the influence of MLLJ winds on ISMR as the previous studies (e.g., Wang and Fan, 1999; Webster and Yang, 1992) suggest that the 850$\mathrm{hPa}$ wind is one of the prime indictor of monsoon. However, the correlation between $925 \mathrm{hPa}$

462 correlations clearly indicate (Figure 14a and f) that the MLLJ is strongly correlated (more than $46395 \%$ confidence) with the mean seasonal ISMR, except over the extreme north and northeastern 464 India and in the monsoon shadow region like Tamil Nadu where north east winter monsoon has a 
465 strong influence. However, there are considerable differences in the correlations between 466 individual mean monthly MLLJ against monthly rainfall compared to seasonal MLLJ against 467 mean seasonal ISMR. The MLLJ strength in June is significantly positively correlated (Figure $46814 \mathrm{~b}$ and $\mathrm{g}$ ) with ISMR rainfall extending from eastern India to northwestern India. The strength 469 of the MLLJ is negatively correlated with southern, northern, and northeastern India in June, and 470 it is positively correlated (more than $95 \%$ confidence) over most of the Indian subcontinent in 471 July, except in the northeastern and central parts of southern India (Figure 14c and h). This 472 suggests that the variability of the MLLJ in July plays an important role in the seasonal monsoon 473 rainfall. In August, the strength of the MLLJ is positively correlated (with 95\% confidence) over 474 the Western Ghats and east central India, but it is negatively correlated with the southern 475 peninsular and north-eastern parts of India. In September, strong positive correlation is observed 476 between the strength of the MLLJ and the rainfall (Figure $14 \mathrm{e}$ and $\mathrm{j}$ ) over the Indian 477 subcontinent, except in the western part of Tamil Nadu and northeastern parts of India (where 478 correlations are negative). Both the WRF model and MERRA show similar patterns between 479 MLLJ intensity at both 925 and $850 \mathrm{hPa}$ (not shown) and ISMR, which suggests that the WRF 480 model reproduces the inter-annual variability of MLLJ as captured in MERRA2.

The correlation analysis clearly indicates that variation in the MLLJ strength alters 482 rainfall patterns over India on a seasonal and sub-seasonal scale. Our 37-year variability 483 analyses, discussed in the previous Sections (from 3.2 to 3.5), suggested that the trend in the 484 strength of MLLJ significantly increases in June, July, and September but decreases during the 485 month of August. This increasing trend in MLLJ strength throughout the three months (June, 486 July, and September) clearly leads to an increase in rainfall over positively correlated regions 487 and a decrease in rainfall over negatively correlated areas, except in the northeastern parts of 
India. Rainfall over the northeastern parts of India is negatively correlated with MLLJ in all months, which indicates that rainfall over this region is independent on MLLJ and probably influenced BOB branch of Monsoon and localized weather phenomena; which requires further investigation. Being in the active phase of monsoon, the declining trend in the strength of MLLJ in August has profound influence on ISMR. Variations in rainfall during August lead to drought conditions over the entire Indian region, which affects the growth of crops (Annamalai and Slingo, 2001; Singh et al. 2014). In addition, it influences rainfall over central India as the monsoon depressions that form over BOB pass through monsoon trough regions.

Monsoon variability has a direct impact on the Indian subcontinent through the occurrence of droughts and floods (Turner, 2012; Niranjan Kumar, 2013). Previous studies on trends in monsoon circulation have suggested that monsoon variability has been higher over the last few decades (Dash et al. 2011; Vinnarasi et al. 2016). These circulation changes have been directly observed in alterations in rainfall over the Indian region (Guhathakurta and Rajeevan, 2008; Naidu et al. 2011; Krishnan et al. 2013) and also in the form of sudden increases in the occurrence of extreme rainfall and flood events (Goswami, 2006; Pattanaik and Rajeevan, 2010; Krishnan et al. 2016). Guhathakurta et al. (2011) examined the variability of extreme rainfall 504 events over India and suggested that the occurrence of these extreme events is highly localized and their frequency is not uniform over a spatial-temporal scale. Most of these events result from

506 low-pressure systems (depressions and cyclones with wind speeds of $\geq 8.5 \mathrm{~m} \mathrm{~s}^{-1}$ ) in BOB, 507 which transports moisture to the central Indian subcontinent, but a declining trend in the 508 variability of these depressions has been noted in recent years (Naidu et al. 2015; Roxy et al. 509 2017; Sandeep et al. 2018). The MLLJ acts as a major source of moisture feeding the monsoon 510 depression formed over the BOB (Nagar et al. 2009; Walker et al. 2015; Roxy et al. 2017), and 
511 therefore, variations in the MLLJ also has a strong influence on the formation of depressions

512 over BOB and the occurrence of extreme rain events over central India (Roxy et al. 2017).

In addition, previous studies on monsoon extremes have indicated that the number of

514 depressions is highly correlated with central India rainfall, suggesting the strong dependence of 515 rainfall on monsoon depressions (Hastenrath and Rosen, 1983; Cohen and Boos, 2014). A time 516 series of the numbers of depressions for individual months (Figure 15a) shows a decreasing trend 517 in August compared to July, indicating a decline in central India rainfall with a decrease in 518 monsoon depressions. This suggests that the decrease in MLLJ strength and number of monsoon 519 depressions (Figure 15b) reduces the amount of rainfall over central India. The observed central 520 India rainfall, the strength of the MLLJ, and the number of monsoon depressions follow a 521 decreasing trend, while the number of break days shows a significant increasing trend in August. 522 Naidu et al. (2011) indicated that the weakening of the zonal wind shear over the BOB $\left(5^{\circ} \mathrm{N}-\right.$ $52322^{\circ} \mathrm{N}$ and $80^{\circ} \mathrm{E}-100^{\circ} \mathrm{E}$ ) between 850 and $100-\mathrm{hPa}$ can lead to a decrease in the frequency of 524 depression and cyclonic systems over the BOB and an associated decrease in the amount of 525 rainfall during monsoon season.

To determine whether the trend in the zonal wind shear is a factor in the decrease of 527 number depression in the month of August, Figure 16 plots the time variation of the zonal wind 528 at 850 and $100 \mathrm{hPa}$ along with its vertical shear during the ISM season and for individual months 529 from June to September. The analysis confirms that the zonal wind at $100 \mathrm{hPa}$ and its vertical 530 shear (difference between 850 and $100 \mathrm{hPa}$ ) exhibit strong decreasing trends $\left(0.1 \mathrm{~m} \mathrm{~s}^{-1} \mathrm{yr}^{-1}\right)$ in 531 August over the past 37 years, and resulting in the weakening of baroclinic instability associated 532 with the tropical easterly jet (Shukla et al. 1978; Rao et al. 2004) has led to a decrease in the 533 number of depressions formed over BOB in August. 
535

536

537

538

539

540

541

542

543

544

545

546

547

548

549

550

551

552

553

554

555

556

Sea and BOB significantly decreases in August, and thus central India rainfall also decreases

compared to the other three months. These results suggest that the decrease in the MLLJ and monsoon depressions in August result in a steep decline in the amount of moisture transported from adjacent seas, which leads to break conditions and an associated deficit in the rainfall over central India. Accordingly, the active phase of the ISMR significantly changes due to the decline in the strength of MLLJ and the total number of monsoon depressions in August.

\section{Summary and conclusions}

The monsoon low level jet (MLLJ) forms and maintains its strength due to the pressure gradient between the heat low over the Indian subcontinent and the Mascarene high during June to September; it plays a dominant role in transporting moisture towards the Indian subcontinent during the Indian Summer Monsoon (ISM). Understanding the structure and characteristics of monsoon circulation across different spatio-temporal scales provides an opportunity to understand the variability of rainfall over the Indian region. This study analyzes the characteristics of monsoon MLLJ and its variability using a dynamically downscaled regional analysis over 37-years (1980-2016) generated using Weather Research Forecasting (WRF) model. Validation of the WRF simulations with available radiosonde station data collected from IGRA indicates that the model reproduces reasonably well the variability in temperature, wind, rainfall, and relative humidity, but it slightly overestimates temperature and winds between the surface and 2-km AGL; these errors are high over the radiosonde stations near to the core of MLLJ (Salala, Mumbai, and Minicoy) and could be attributed to variations between the height and the intensity of the simulated jet and radiosonde observations. The major conclusions resulting from the MLLJ analysis on a diurnal to inter-annual scales are summarized as follows: 
557 1. The MLLJ exhibits distinct diurnal variability with respect to both intensity and height of 558 jet. There is a clear difference between the diurnal characteristics of synoptic scale MLLJ winds and orographically driven low-level jet winds of a monsoon origin over Sudan, the Red Sea, and the windward and leeward side of the Western Ghats. The synoptic scale jet of the MLLJ shows a maximum during daytime (at 0600 UTC), while the orographic channeled jets show a peak in the late evening and during the night hours (1800 UTC and 0000 UTC).

2. Strong correlations between the diurnal variability of winds and maximum day-time rainfall found over the windward side of the Western Ghats and a maximum night-time rainfall occurring over central India is noticed. It is due to the fact that the diurnal variations in the winds amplify the moisture gradients in the LLJ outflow region, resulting in the moisture convergence and the formation of convection systems and rainfall.

3. Compared to MERRA2 reanalyzed fields, the WRF simulations well capture the spatial distribution of JJAS winds albeit to a slight increase in intensities ( 2 to $3 \mathrm{~m} \mathrm{~s}^{-1}$ ) of MLLJ over the eastern Arabian Sea and the Bay of Bengal. The mean monthly wind differences between MERRA2 and WRF clearly demonstrate the advantage of regional climate downscaling, with an enhanced channeled flow observed in the mountain gaps of the East-African and Gulf of Aden. The increase mountain gap winds over Gulf of Aden are one of the contributing factors for spatial extension of MLLJ over western Arabian Sea.

4. Moreover, the comparison of MLLJ winds during strongest La-Nina and El-Nina years reveal that the spatial extent and intensity of the LLJ core over western Arabian is higher 
during the La-Nino years while the stronger winds spread to higher pressure levels over Peninsular India and BOB are seen during El-Nino years.

5. A sub-seasonal analysis of WRF winds and those of MERRA2 suggests that the MLLJ attains its maximum strength and spatial extent in July and August. The maximum spatial extent of MLLJ in the peak months could be due to the merging of orographically driven winds from the Red Sea with those of the Somali jet.

6. A comparison of the variability of mean MLLJ winds during 37-years between the WRF and MERRA2 suggests that the WRF simulated winds capture the variability of MLLJ winds both upper and lower levels with slight overestimations at lower levels. The higher gradients of pressure simulated at lower levels lead to slight overestimation of winds at lower levels.

7. Variability of the MLLJ (at $850 \mathrm{hPa}$ ) is strongly correlated (more than $95 \%$ confidence) with mean ISMR on both seasonal and sub-seasonal scales, except over the regions of extreme north and northeastern India and Tamil Nadu.

8. The strength of the MLLJ exhibits a significantly decreasing trend in August. The combined effect of the weakened MLLJ and the decrease in the number of depressions in BOB during August suppress the ISMR due to reduced moisture transport from BOB and the Arabian Sea, which in turn leads to an increased number of break conditions.

This study therefore concludes that the decreasing trend in the strength of MLLJ during August has a profound influence on the number of depressions formed over the North Indian Ocean, which in turn regulates the active phase of the ISM. In addition, the decreasing trend in the number of depressions leads to prolonged break conditions and suppression of rainfall over the Indian subcontinent. 
602

603

604

605

606

607

608

609

610

611

612

613

614

615

616

617

618

619

620

621

622

623

624

625

626

627

628

629

630

\section{Acknowledgments}

Authors sincerely thank India Meteorological Department, Government of India, for providing the high resolution gridded rainfall, surface synoptic data and the number of depressions and cyclones over north Indian Ocean. The third author acknowledges Science and Engineering Research Board (SERB), Department of Science and Technology (DST), Government of India for providing necessary funds (PDF/2016/003854) to carry out this work. This research made use of the Supercomputing Laboratory resources available at King Abdullah University of Science and Technology (KAUST), Kingdom of Saudi Arabia. The authors gratefully acknowledge the anonymous reviewers for constructive suggestions and comments during the review process.

\section{References:}

Aneesh S, Sijikumar S. 2016. Changes in the south Asian monsoon low level jet during recent decades and its role in the monsoon water cycle. Journal of Atmospheric and Solar-Terrestrial Physics 139: 47-53, doi:10.1016/j.jastp.2015.12.009.

Annamalai H, and Slingo JM. 2001. Active/break cycles: Diagnosis of the intraseasonal variability of the Asian Summer Monsoon. Clim. Dynam. 18, 85-102.

Atlas R, Hoffman RN, Ardizzone J, Leidner SM, Jusem JC, Smith DK, Gombos D. 2011. A cross-calibrated, multiplatform ocean surface wind velocity product for meteorological and oceanographic applications. Bull. Amer. Meteor. Soc. 92: 157-174. doi: 10.1175/2010BAMS2946.1.

Attada R, Kumar P, Dasari HP. 2018. Assessment of Land Surface Models in a High-Resolution Atmospheric Model during Indian Summer Monsoon. Pure Appl. Geophys. 1-26, doi:10.1007/s00024-018-1868-z

Basu BK. 2007. Diurnal Variation in Precipitation over India during the Summer Monsoon Season: Observed and Model Predicted. Mon. Wea. Rev. 135, 2155-2167.

Boos WR, and Emanuel KA 2009. Annual intensification of the. Somali jet in a quasiequilibrium framework: observational composites. Q. J. R. Meteorol. Soc., 135, 319-335.

Bryan SP, Hughen KA, Karnauskas KB, and Farrar JT. 2019. Two hundred fifty years of reconstructed South Asian summer monsoon intensity and decadal-scale variability. Geophysical Research Letters, 46, 3927-3935, doi:10.1029/2018GL081593. 
631 Cadet D, and Reverdin G. 1989. Water vapour transport over the Indian Ocean during summer 632 1975. Tellus. 33: 476-487. doi:10.1111/j.2153-3490.1981.tb01773.x

633 Chen R, and Tomassini L. 2015. The role of moisture in summertime low-level jet formation and 634 associated rainfall over the East Asian Monsoon region. J. Atm. Sci. 72, 3871- 3890, 635 doi:10.1175/JAS-D-15-0064.1

636 Chen X, Pauluis OM, and Zhang F. 2018. Regional simulation of Indian summer monsoon 637 intraseasonal oscillations at gray-zone resolution, Atmos. Chem. Phys. 18, 1003-1022, 638 doi:10.5194/acp-18-1003-2018.

639 Cohen NY, and Boos WR. 2014. Has the number of Indian summer monsoon depressions 640 decreased over the last 30 years?, Geophys. Res. Lett. 41, 7846-7853.

641 Dasari HP, D Srinivas, L Sabique, A Raju, Yesubabu V, Ravikumar K, I Hoteit. 2019: 642 Assessment of solar radiation resources and its variability over Arabian Peninsula. Applied 643 Energy, 248, 354-371.

644 Dash SK, Nair AA, Kulkarni Makarand A, Mohanty UC. 2011. Characteristic changes in the 645 long and short spells of different rain intensities in India. Theor. Appl. Climatol. 105(3-4): 563646570.

647 Dee DP, Uppala SM, Simmons AJ, Berrisford P, Poli P, et al. 2011. The ERA-Interim reanalysis: 648 configuration and performance of the data assimilation system. Q. J. R. Meteorol. Soc. 137(656): 649 553-597, doi: 10.1002/qj.828.

650 Singh D, Tsiang M, Rajaratnam B, Diffenbaugh Noah S. 2014. Observed changes in extreme 651 wet and dry spells during the South Asian summer monsoon season. Nature Climate Change, 4 , 652 456-461, doi: 10.1038/nclimate2208.

653 Deshpande NR, and Goswami BN. 2014. Modulation of the diurnal cycle of rainfall over India 654 by intraseasonal variations of Indian summer monsoon. Int. J. Climatol. 34: 793-807.

655

656 657

658

659

660

661

662

663

664

Du Y, Chen Y, and Zhang Q. 2015. Numerical Simulations of the Boundary Layer Jet off the Southeastern Coast of China. Mon. Wea. Rev. 143:1212-1231, doi:10.1175/MWR-D-14$\underline{00348.1}$

Dwivedi S, Narayanan MS, Venkat Ratnam M, Narayana Rao D. 2016. Characteristics of monsoon inversions over the Arabian Sea observed by satellite sounder and reanalysis data sets Atmospheric Chemistry and Physics, 16:4497-4509. doi:10.5194/acp-16-4497-2016.

Narayanan MS, Rao BM. 1989. Stratification and convection over Arabian Sea during monsoon 1979 from satellite data. Proceedings of the Indian Academy of Sciences-Earth and Planetary Sciences 98(4): 339-352. Findlater, J. 1969. A major low-level air current near the Indian Ocean during the northern summer. Q.J.R. Meteorol. Soc. 95: 362-380. doi:10.1002/qj.49709540409 
665 Gadgil S. 2006. The Indian Monsoon, GDP and agriculture. Econ Polit Weekly. Nov 25; 41(47): $666 \quad 4887-4895$.

667 Gelaro R, McCarty W, et al. 2017. The Modern-Era Retrospective Analysis for Research and 668 Applications, Version 2 (MERRA-2). J. Climate 30, 5419-5454, doi:10.1175/JCLI-D-16-0758.1

669 Giorgi F, and Mearns LO. 1991. Approaches to regional climate change simulation: A review. 670 Rev. Geophys., 29, 191-216, doi:10.1029/90RG02636.

671 Giorgi F. 2006. Regional climate modeling: Status and perspectives. J. Phys., 139, 101-118, doi: $672 \quad 10.1051 / j p 4: 2006139008$.

673 Goswami BN, Venugopal V, Sengupta D, Madhusoodanan M, and Xavier PK. 2006. Increasing 674 trend of extreme rain events over India in a warming environment. Science. 314, 1442-1445.

675 Guhathakurta P, and Rajeevan M. 2008. Trends in the rainfall pattern over India. Int. J. Climatol. 676 28: 1453-1469. doi:10.1002/joc.1640.

677 Guhathakurta, P. Sreejith, O. and Menon, P. 2011. Impact of climate change on extreme rainfall 678 events and flood risk in India. J. Earth System Sci. 120, 359. doi:10.1007/s12040-011-0082-5.

679 Hari Prasad D, Rui Salgado, Joao Perdigao, and Venkata Srinivas C. 2014. A Regional Climate 680 Simulation Study Using WRF-ARW Model over Europe and Evaluation for Extreme 681 Temperature Weather Events. International Journal of Atmospheric Sciences. 2014 (704079), 22, 682 doi:10.1155/2014/704079.

683 Hart JE. 1977. On the theory of the East African low level jet stream. Pure Appl. Geophys. 115, $684 \quad 1263-1282$.

685 Huffman GJ, Adler RF, Curtis S, Bolvin DT, Nelkin EJ. 2007. Global rainfall analyses at 686 monthly and 3-hr time scales. Chapter 23 of Measuring Precipitation from Space: EURAINSAT 687 and the Future, V. Levizzani, P. Bauer, and F.J. Turk, Eds., Springer Verlag (Kluwer Academic 688 Pub. B.V.), Dordrecht, The Netherlands, 291-306.

689 Hastenrath S, and Rosen A. 1983. Patterns of India monsoon rainfall anomalies. Tellus A, 35A: 690 324-331. doi:10.1111/j.1600-0870.1983.tb00206.x

691

692 693

694 695

696 697
Heikkilä U, Sandvik A, Sorteberg A. 2011. Dynamical downscaling of ERA-40 in complex terrain using the WRF regional climate model. Clim Dyn. 37: 1551, doi: 10.1007/s00382-0100928-6.

Hima Bindu H, Venkat Ratnam M, Viswanadhapalli Y, and Hari Prasad D. 2018. Medium frequency gravity wave characteristics obtained using Weather Research and Forecasting (WRF) model simulations, Journal of Atmospheric and Solar-Terrestrial Physics, 182: 119 - 129, doi:10.1016/j.jastp.2018.11.013 
698 Iacono MJ, Delamere JS, Mlawer EJ, Shephard MW, Clough SA, and, Collins WD. 2008.

699

700

701

702

703

704

705

706

707

708

709

710

711

712

713

714

715

716

717

718

719

720

721

722

723

724

725

726

727

728

729

Radiative forcing by long-lived greenhouse gases: Calculations with the AER radiative transfer models. J. Geophys. Res. 113, D13103, doi: 10.1029/2008JD009944.

Jain SK, and Kumar V. 2012. Trend analysis of rainfall and temperature data for India, Current Science 102, 588 37-49.

Janjic ZA. 1994. The step-mountain ETA coordinate model: further development of the convection, viscous sublayer and turbulence closure scheme. Mon. Wea. Rev. 122 (5), 927-945.

Jiang H, Farrar JT, Beardsley RC, Chen R, and Chen C. 2009. Zonal surface wind jets across the Red Sea due to mountain gap forcing along both sides of the Red Sea. Geophys. Res. Lett. 36, L19605, doi:10.1029/2009GL040008. Joseph PV, and Sijikumar S. 2004. Intraseasonal variability of the low level jet stream of the Asian summer monsoon. J. Climate 17, 1449-1458.

Krishnamurthy V, and Ajayamohan RS. 2010. Composite structure of monsoon low pressure systems and its relation to Indian rainfall, J. Climate 23 (16), 4285-4305.

Krishnamurti TN. and Bhalme HN. 1976. Oscillations of a Monsoon System, Part 1: Observational Aspects. J. Atmos. Sci. 33: 1937-1954.

Krishnamurti TN, Molinari J, Pan LH. 1976. Numerical Simulation of the Somali Jet. J. Atmos. Sci. 33(12): 2350-2362.

Krishnamurti TN, Wong V, Pan HL, Pasch R, Molinari J, Ardanuy P. 1983. A three-dimensional planetary boundary-layer model for the Somali Jet. J. Atmos. Sci. 40: 894-908.

Krishnan R, et al. 2013. Will the South Asian monsoon overturning circulation stabilize any further? Clim Dyn. 40:1-2, pp. 187-211.

Krishnan R, Sabin TP. et al. 2016. Deciphering the desiccation trend of the South Asian monsoon hydroclimate in a warming world, Clim Dyn. 2016. 47: 1007. doi:10.1007/s00382-0152886-5

Lo JCF, Yang ZL, Pielke RA Sr. 2008. Assessment of three dynamical climate downscaling methods using the weather research and forecasting (WRF) model. J. Geophys Res. 113:D09112. doi: 10.1029/2007JD00921

Lucas-Picher P, Fredrik Boberg, Jens H Christensen, and Peter B. 2013. Dynamical Downscaling with Reinitializations: A Method to Generate Finescale Climate Datasets Suitable for Impact Studies. J. Hydrometeor, 14, 1159-1174. doi: http://dx.doi.org/10.1175/JHM-D-12-063.1

Martin AC, Krishnamurti TN, and Lau WKM. 2013. Absorbing aerosol-induced change in the early monsoon Arabian Sea low-level jet: Modeled transfer from anomalous heating 
730 tonondivergent kinetic energy, J. Geophys. Res. Atmos 118, 12,566-12,576, 731 doi:10.1002/2013JD019808.

732 Mukhopadhyay P, Taraphdar S, Goswami BN, Krishnakumar K. 2010. Indian summer monsoon 733 precipitation climatology in a high-regional climate model: impacts of convective 734 parameterization on systematic biases. Weather and Forecasting 25: 369-387.

735 Murakami T. 1976. Analysis of summer monsoon fluctuations over India. J Met Soc Japan 54, $736 \quad 15-31$.

737 Nagar S, Bawiskar S, Chinthalu G, et al. 2009. Study of Dynamical Structure of an Unusual 738 Monsoon Depression formed over the Bay of Bengal during August 2006 Pure appl. geophys. 739 166(3):485-507 . doi:10.1007/s00024-009-0446-9

740 Naidu CV, Durgalakshmi K, Satyanarayana GCh, Malleswara Rao L, Ramakrishna SSVS, 741 Mohan JR, Naga Ratna K. 2011. An observational evidence of climate change during global 742 warming era. Global and Planetary Change 79 (1-2): 11-19.

743 Naidu CV, Dharma Raju A, Satyanarayana G, Vinay Kumar P, Chiranjeevi G, Suchitra P. 744 (2015). An observational evidence of decrease in Indian summer monsoon rainfall in the recent 745 three decades of global warming era. Global and Planetary Change, 127, 91-102.

746 Nair SK, Prabha TV, Purushothaman N. et al. 2015. Diurnal variations of the low-level jet over 747 peninsular India during the onset of Asian summer monsoon, Theor. Appl. Climatol. 120: 287. 748 doi:10.1007/s00704-014-1168-1.

749 Nakanishi M, Niino H. 2004. An improved Mellor-Yamada level-3 model with condensation 750 physics: its design and verification. Bound.Layer Meteorol. 112:1-31.

751 Niranjan Kumar K, Rajeevan M, Pai DS, Srivastava AK, and Preethi B. 2013. On the observed 752 variability of monsoon droughts over India. Weather and Climate Extremes 1:42-50. 753 doi:10.1016/j.wace.2013.07.006

754 Niu G-Y, et al. 2011. The community Noah land surface model with multiparameterization 755 options (Noah-MP): 1. Model description and evaluation with local-scale measurements. J. 756 Geophys. Res. 116, D12109, doi: 10.1029/2010JD015139.

757 Parthasarathy B, and Mooley DA. 1978. Some features of a long homogeneous series of Indian 758 summer monsoon rainfall. Mon. Wea. Rev. 106.771-781.

759 Parthasarathy B, Munot AA, and Kothawale DR. 1995. Monthly and seasonal rainfall series for 760 all-India, Homogeneous Regions and Meteorological subdivisions: 1871-1994. IIIN 0252-1075, 761 Research Report No. RR-065. 
762 Pattanaik D, and Rajeevan M. 2010. Variability of extreme rainfall events over India during southwest monsoon season. Meteorol. Appl. 17, 88-104.

764

765

766

767

768

769

770

771

772

773

774

775

776

777

778

779

780

781

782

783

784

785

786

787

788

789

790

791

792

793

794

Pattnayak KC, Panda SK, Dash SK. 2013. Comparative study of regional rainfall characteristics simulated by RegCM3 and recorded by IMD, Global and planetary change, 106, 111-122.

Pattnayak KC, Panda SK, Saraswat V, and Dash SK. 2016. Relationship between tropospheric temperature and Indian summer monsoon rainfall as simulated by RegCM3, Climate dynamics, 46 (9-10), 3149-3162.

Prabha TV, Goswami BN, Murthy BS, and Kulkarni JR. 2011. Nocturnal low-level jet and 'atmospheric streams' over the rain shadow region of Indian Western Ghats. Q.J.R. Meteorol. Soc. 137: 1273-1287. doi:10.1002/qj.818

Rajeevan M, Kesarkar A, Thampi SB, Rao TN, Radhakrishna B, Rajasekhar M. 2010. Sensitivity of WRF cloud microphysics to simulations of severe thunderstorm event over Southeast India. Ann. Geophys. 28, 603-619.

Rajendran K, Kitoh A, Srinivasan J, Mizuta R, Krishnan R. 2012. Monsoon circulation interaction with Western Ghats orography under changing climate. Theor Appl Climatol. 110, 555-571. doi:10.1007/s00704-012-0690-2

Raju A, Parekh A, and Gnanaseelan, C. 2014. Evolution of vertical moist thermodynamic structure associated with the Indian summer monsoon in a regional climate model.Pure Appl. Geophys. 171: 1499-1518. doi:10.1007/s00024-013-0697-3.

Raju A, Parekh A, Chowdary JS, Gnanaseelan C. 2015. Assessment of the Indian summer monsoon in the WRF regional climate model. Climate Dyn. 44 (11-12): 3077-3100.

Ramaswamy V, Muraleedharan PM, Babu CP. 2017. Mid-troposphere transport of Middle-East dust over the Arabian Sea and its effect on rainwater composition and sensitive ecosystems over India. Scientific Reports 7(1): 1-8.

Rao BRS, Rao DVB, and Rao VB. 2004. Decreasing trend in the strength of Tropical Easterly Jet during the Asian summer monsoon season and the number of tropical cyclonic systems over Bay of Bengal. Geophys. Res. Lett. 31, L14103, doi:10.1029/2004GL019817.

Raymond DJ. 1978. Instability of the Low-Level Jet and Severe Storm Formation. J. Atmos. Sci. 35(12):2274-2280.

Rodwell MJ, Hoskins BJ. 1995. A model of the Asian summer monsoon. Part II: Crossequatorial flow and PV behavior. J. Atmos. Sci. 52: 1341-1356.

Rojas M, and Seth A. 2003. Simulation and sensitivity in a nested modeling system for South America. Part II: GCM boundary forcing. J. Climate 16, 2454-2471. 
Roja Raman M, Venkat Ratnam M, Rajeevan M, Jagannadha Rao VV, Bhaskara Rao SV. 2011. Intriguing Aspects of the Monsoon Low-Level Jet over Peninsular India Revealed by HighResolution GPS Radiosonde Observations. J. Atmos. Sci., 68, 1413-1423.

Roxy M, Subimal Ghosh, Amey Pathak, Athulya R, Milind Mujumdar, et al. 2017. A threefold rise in widespread extreme rain events over central India. Nature Communications. 8 (708), doi: 10.1038/s41467-017-00744-9.

Ruchith RD, Raj PE, Kalapureddy MCR, Deshpande SM, and Dani KK. 2014. Time evolution of monsoon low-level jet observed over an Indian tropical station during the peak monsoon period from high-resolution Doppler wind lidar measurements. J. Geophys. Res. Atmos. 119, 17861795, doi: 10.1002/2013JD020752.

Sabeerali CT, Rao SA, Ajayamohan RS, and Murtugudde R. 2012. On the relationship between Indian summer monsoon withdrawal and Indo-Pacific SST anomalies before and after 1976/1977 climate shift. Climate Dyn. 39, 841-859, doi:10.1007/s00382-011-1269-9.

Sam NV, and Vittal Murty KPR. 2002. Characteristics of monsoon low level jet (MLLJ) as an index of monsoon activity. Proc. Indian Acad. Sci. 4, 453-457.

Samala BK, Nagaraju C, Banerjee S, Kaginalkar A, Dalvi M. 2013. Study of the Indian summer monsoon using WRF-ROMS regional coupled model simulations, Atmospheric Science Letters, 14: $20-27$.

Sandeep S, Ajayamohan RS, William R Boos, Sabin TP, Praveen V. 2018. Decline and poleward shift in Indian summer monsoon synoptic activity in a warming climate, Proceedings of the National Academy of Sciences. 2681-2686; doi: 10.1073/pnas.1709031115.

Sandeep S, and Ajayamohan RS. 2015. Poleward shift in Indian summer monsoon low level jetstream under global warming. Clim Dyn. 45:337-351.

Sathiyamoorthy V, Mahesh C, Gopalan K, Prakash S, Shukla BP, Mathur A. 2013. Characteristics of low clouds over the Arabian Sea. J. Geophys. Res. Atmos. 118(13): 489413,503 .

Sen Roy S, and Balling RC. 2004. Trends in extreme daily precipitation indices in India. Int. J. Climatol. 24: 457-466. doi:10.1002/joc.995.

Shukla J. 1978. CISK barotropic-baroclinic instability and the growth of monsoon depressions. J. Atmos. Sci. 35, 495-508.

Srinivas CV, Hariprasad D, Bhaskar Rao DV, Anjaneyulu Y, Baskaran R, Venkatraman B. 2013. Simulation of the Indian summer monsoon regional climate using advanced research WRF model. Int. J. Climatol. 33:1195-1210. 
Srinivas CV, Bhaskar Rao DV, Hari Prasad D, Hari Prasad KBRR, R Baskaran, Venkatraman B. 2015. A study on the influence of the Land Surface Processes on the Southwest Monsoon simulations using a Regional Climate model, Pure Appl. Geophys. 172(10): 2791-2811.

Srinivas CV, Yesubabu V, Hari Prasad D, Hari Prasad KBRR, Greeshma MM, Baskaran R, Venkatraman B. 2018. Simulation of Heavy Rainfall Event over Chennai, India using WRF: Sensitivity to grid resolution and boundary layer physics. Atmos. Res. 210: 66-82, doi:10.1016/j.atmosres.2018.04.014.

Thompson G, Field PR, Rasmussen RM, Hall WD. 2008. Explicit forecasts of winter precipitation using an improved bulk microphysics scheme. Part II: implementation of a new snow parameterization. Am. Meteorol. Soc. 136, 5095-5115.

Tucker M, and Pedgley D. 1977. Summer winds around the southern Red Sea. Theor. Appl. Climatol. 25(3): 221-231

Turner AG, and Annamalai H 2012. Climate Change and the South Asian Monsoon, Nature Climate Change 2: 587-595, doi:10.1038/nclimate1495.

Vellore RK, Kaplan ML, Krishnan R. et al. 2016. Monsoon-extratropical circulation interactions in Himalayan extreme rainfall. Clim Dyn. 46: 3517-3546. doi:10.1007/s00382-015-2784-x

Vinnarasi R, and Dhanya C. 2016. Changing characteristics of extreme wet and dry spells of Indian monsoon rainfall. J. Geophys. Res. Atmos. 121, 2146-2160.

Viste E, and Sorteberg A. 2013. The effect of moisture transport variability on Ethiopian summer precipitation. Int. J. Climatol. 33: 3106-3123. doi:10.1002/joc.3566

Viswanadhapalli Y, Dasari HP, Langodan S, Challa VS, and Hoteit I. 2017. Climatic features of the Red Sea from a regional assimilative model. Int. J. Climatol. 37: 2563-2581. doi:10.1002/joc.4865.

Walker JM, Bordoni S, Schneider T. 2015. Interannual variability in the large-scale dynamics of the South Asian summer monsoon. J. Clim. 28, 3731-3750.

Wang B, and Fan Z. 1999. Choice of South Asian Summer Monsoon Indices. Bull. Amer. Meteor. Soc., 80, 629-638, doi:10.1175/1520-0477.

Wang B, Liu J, Kim HJ, Webster PJ, Yim SY, Xiang B. 2013. Northern Hemisphere summer monsoon intensified by mega-El Nino/southern oscillation and Atlantic multidecadal oscillation. Proceedings of the National Academy of Sciences. 110(14):5347-5352.

Washington MW, and Daggupaty SM. 1975. Numerical simulation with the NCAR global circulation model of the mean conditions during the Asain-African summer monsoon. Mon. Wea. Rev. 103: 105-114. doi:10.1175/1520-0493(1975)103. 
861 Webster PJ, and Yang S. 1992. Monsoon and ENSO: Selectively interactive systems. Quart. J. 862 Roy. Meteor. Soc., 118, 877 - 926.

863 Wu Y, Raman S, Mohanty UC. 1999. Numerical investigation of the Somali jet interaction with 864 the Western Ghat Mountains. Pure Appl. Geophys. 154, 365-396,

865 Xavier A, Kottayil A, Mohanakumar K, and Xavier PK. 2018. The role of monsoon low-level jet 866 in modulating heavy rainfall events. Int. J. Climatol 38: 569-576. doi:10.1002/joc.5390.

867 List of Figures with captions

868 Figure 1. a) Spatial extent of WRF model domain (18-km) configured for study; shaded areas 869 indicate topography and the color circles show the locations of radiosonde stations used for the 870 model validation and b) Schematic diagram of prevailing wind systems during JJAS months.

871 Figure 2. Statistical profiles of bias and RMSE calculated using WRF against radiosonde station 872 data.

873 Figure 3. Day-height sections of statistical profiles of (a) RMSE and (b) bias at Minicoy 874 radiosonde station.

875 Figure 4. Spatial patterns of 6-hourly $925 \mathrm{hPa}$ winds at (a) $0000 \mathrm{UTC}$, (b) $0600 \mathrm{UTC}$, (c) 1200 876 UTC, and (d) 1800 UTC averaged for JJAS months of 37-years.

877 Figure 5. Time-height sections of 37-year mean winds at (a, c) 0000 UTC, and (b, d) 1200 UTC 878 from WRF (top panels) and radiosonde (bottom panels) plotted at Minicoy.

879 Figure 6. Spatial distribution of 6-hourly rainfall $(\mathrm{mm} / \mathrm{h})$ at $(\mathrm{a}, \mathrm{b}) 0000 \mathrm{UTC},(\mathrm{c}, \mathrm{d}) 0600 \mathrm{UTC}$, 880 (e, f) $1200 \mathrm{UTC}$, and (g, h) 1800 UTC from WRF (top panels) and TRMM (bottom panels).

881 Figure 7. 37-year mean JJAS winds plotted for surface (a, d), $925 \mathrm{hPa}(\mathrm{b}, \mathrm{e})$ and $850 \mathrm{hPa}(\mathrm{c}, \mathrm{f})$ 882 levels. Wind magnitude shown in shaded and direction as vector.

883 Figure 8. Pressure latitude and longitude sections of 37-year mean JJAS winds from MERRA2 884 (left panels) and WRF (right panels). Horizontal wind magnitude shown in shaded and direction 885 as vector.

886 Figure 9. Composite of JJAS winds (at $850 \mathrm{hPa}$ ) plotted during (a, e) Strong La Niña years, (b,d) 887 Strong El Niña years, and (c, f) difference between La- Niña and El Niña years.

888 Figure 10. Spatial variation of 37-year mean monthly winds (at $850 \mathrm{hPa}$ ) from MERRA2 (right 889 panels) WRF (middle panels) and the respective wind differences between WRF and MERRA 890 (left panels). 
891 Figure 11. Longitude- pressure sections of 37-year mean monthly winds at latitude $\left(10^{\circ} \mathrm{N}\right)$ from 892 (a,b) June, (c, d) July, (e, f) August, and (g, h) September.

893 Figure 12. Time series of MERRA2 and WRF winds averaged over the core region of MLLJ 894 (i.e., $10^{\circ} \mathrm{N}-15^{\circ} \mathrm{N}$ and $50^{\circ} \mathrm{E}-60^{\circ} \mathrm{E}$ ) at (a) $925 \mathrm{hPa}$, (b) $900 \mathrm{hPa}$, (c) $850 \mathrm{hPa}$, and (d) $700 \mathrm{hPa}$ 895 levels.

896 Figure 13. Time series of monthly mean $925 \mathrm{hPa}$ (left panels) and $850 \mathrm{hPa}$ (right panels) winds 897 of MLLJ during (a, b) June; (c, d) July; (e, f) August; and (g, h) September.

898 Figure 14. Spatial distributions of correlation coefficients computed using the strength of MLLJ 899 (at $850 \mathrm{hPa}$ ) and the corresponding observed ISMR.

900 Figure 15. Variations in the number of depressions over Bay of Bengal and number of days 901 associated with break conditions during 1980-2016 July and August months.

902 Figure 16. Variation of zonal wind $(\mathrm{m} / \mathrm{s})$ during the entire ISM season and for individual months 903 at $850 \mathrm{hPa}$ (left panels), at $100 \mathrm{hPa}$,(middle panels) and vertical zonal wind shear (in $\mathrm{m} / \mathrm{s}$ ) 904 between $850 \mathrm{hPa}$ and $100 \mathrm{hPa}$ levels (left panels).

905 List of Supplementary Figures with captions

906 Figure S1. Longitudinal pressure sections of mean JJAS winds at latitude $10^{\circ} \mathrm{N}$ (left panel) and $90713^{\circ} \mathrm{N}$ (right panel) at $0000 \mathrm{UTC}(\mathrm{a}, \mathrm{b}) ; 0600 \mathrm{UTC}(\mathrm{c}, \mathrm{d}) ; 1200 \mathrm{UTC}(\mathrm{e}, \mathrm{f})$ and $1800 \mathrm{UTC}(\mathrm{g}, \mathrm{h})$.

908 Figure S2. Spatial patterns of 6-hourly winds (925 hPa) over Indian Peninsular.

909 Figure S3. Same as Figure 4 but plotted at $850 \mathrm{hPa}$ level.

910 Figure S4. Longitudinal height-section of JJAS winds (m/s) plotted at latitude $20^{\circ} \mathrm{N}$ at (a) 0000 911 UTC, (b) 0600 UTC, (c) 1200 UTC, and (d) 1800 UTC.

912 Figure S5. Spatial distribution of 6-hourly monthly winds shown at (a) 0000 UTC, (b) 0600 913 UTC, (c) 1200 UTC, and (d) 1800 UTC.

914 Figure S6. Composite of JJAS winds (at $850 \mathrm{hPa}$ ) plotted during (a, e) Moderate to week La 915 Niña years, $(b, d)$ Moderate to week El Niña years, and $(c, f)$ difference between the moderate to 916 week La- Niña and El Niña years.

917 Figure S7. Longitudinal height-section of mean winds at latitude $\left(10^{\circ} \mathrm{N}\right)$ from June to September 918 plotted during a) El- Niña and b) La- Niña years.

919 Figure S8. Longitudinal height-section of monthly mean winds at latitude $\left(13^{\circ} \mathrm{N}\right)$ from June to 920 September. 
921 Figure S9. Spatial pattern of trends (1980-2016) in surface temperature (shown in shaded; ${ }^{\circ} \mathrm{C}$ ) 922 and mean sea level pressure (shown in contour; $\mathrm{hPa}$ )

923 Figure S10. Analysis of trends in monthly mean temperature $\left({ }^{\circ} \mathrm{C} /\right.$ year$)$ and geopotenital heights 924 shown in contour (m/year) at 850-hPa during a) June, b) July, c) August and d) September. 


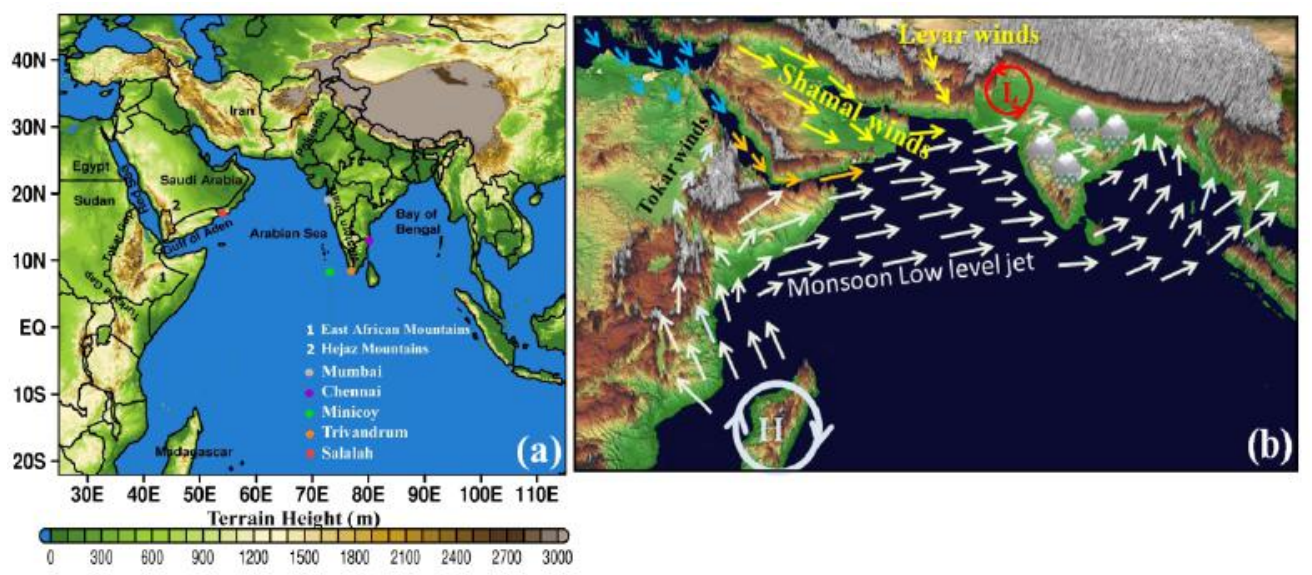

Figure 1. a) Spatial extent of WRF model domain (18-km) configured for study; shaded areas indicate topography and the color circles show the locations of radiosonde stations used for the model validation and b) Schematic diagram of prevailing wind systems during JJAS months.

$345 \times 152 \mathrm{~mm}(300 \times 300 \mathrm{DPI})$ 

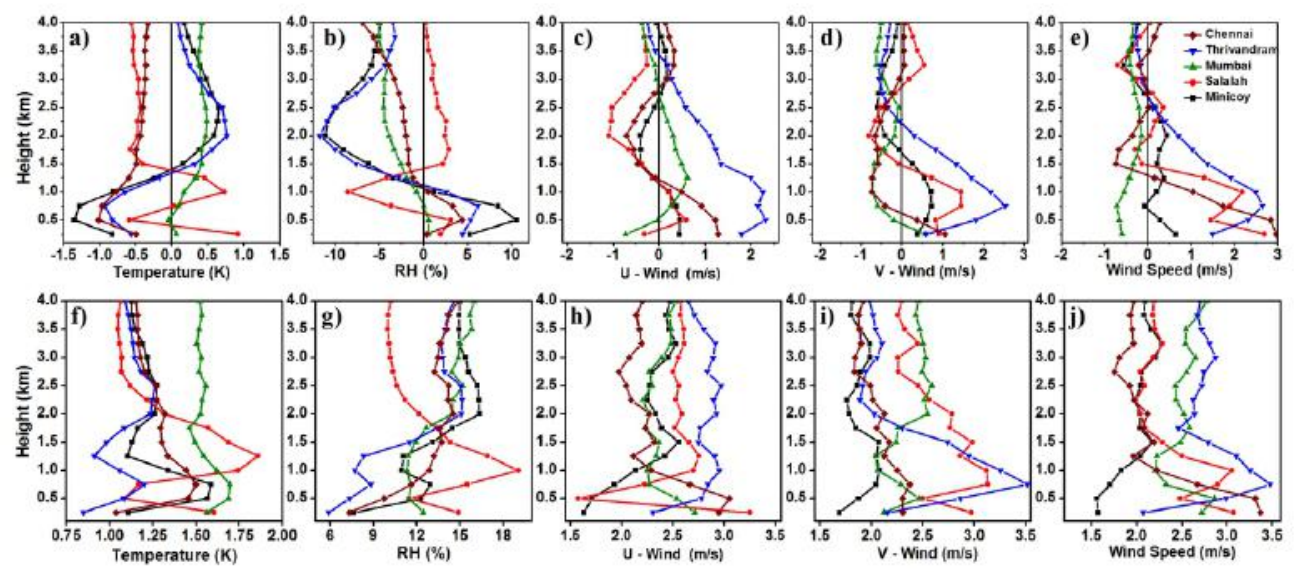

Figure 2. Statistical profiles of bias and RMSE calculated using WRF against radiosonde station data.

$238 \times 108 \mathrm{~mm}(300 \times 300$ DPI $)$ 
a) BIAS

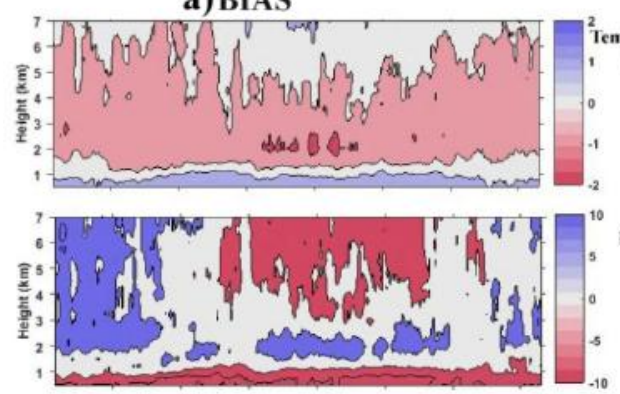

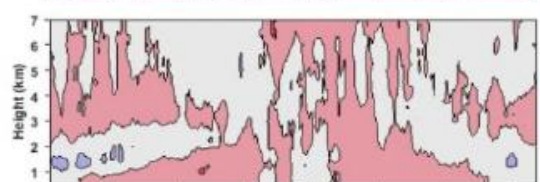
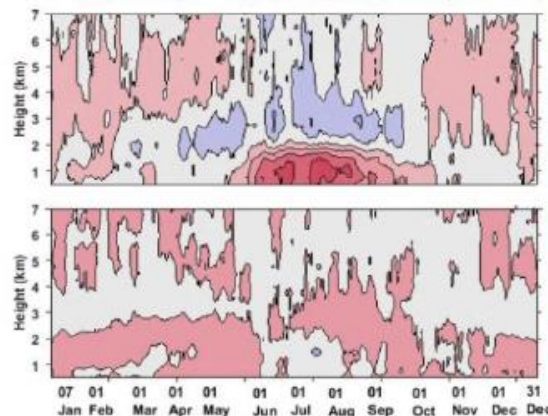

b) RMSE

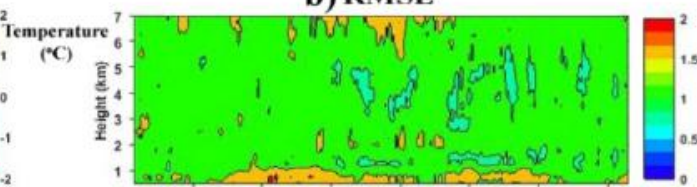

RH (\%) 6
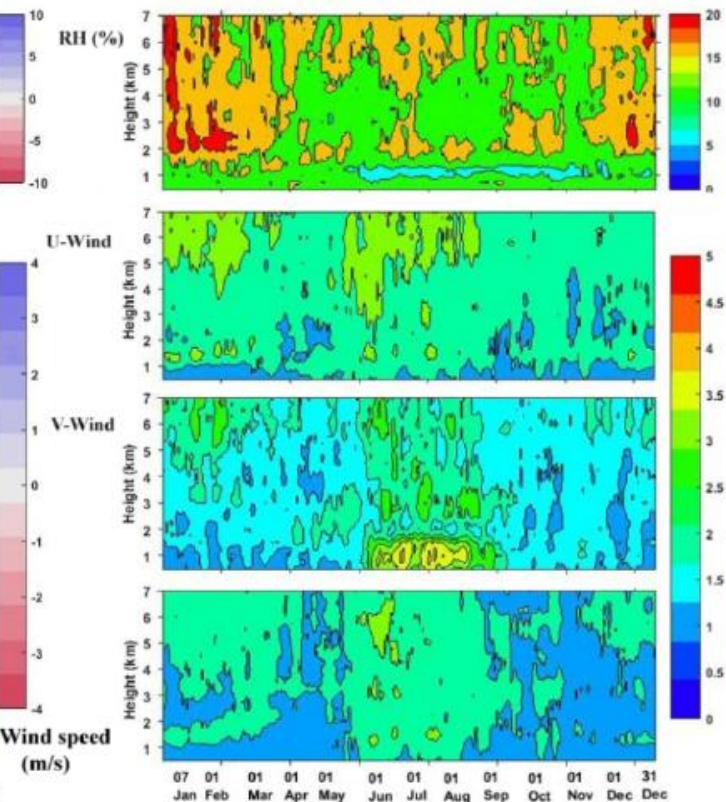

Figure 3. Day-height sections of statistical profiles of (a) RMSE and (b) bias at Minicoy radiosonde station. $101 \times 83 \mathrm{~mm}(300 \times 300 \mathrm{DPI})$ 

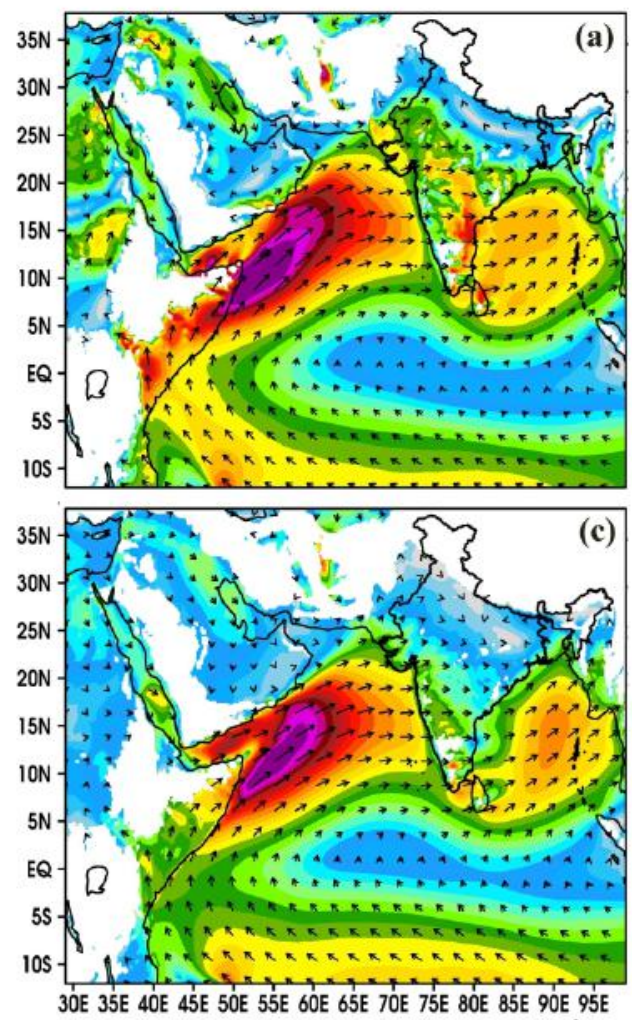

(c)
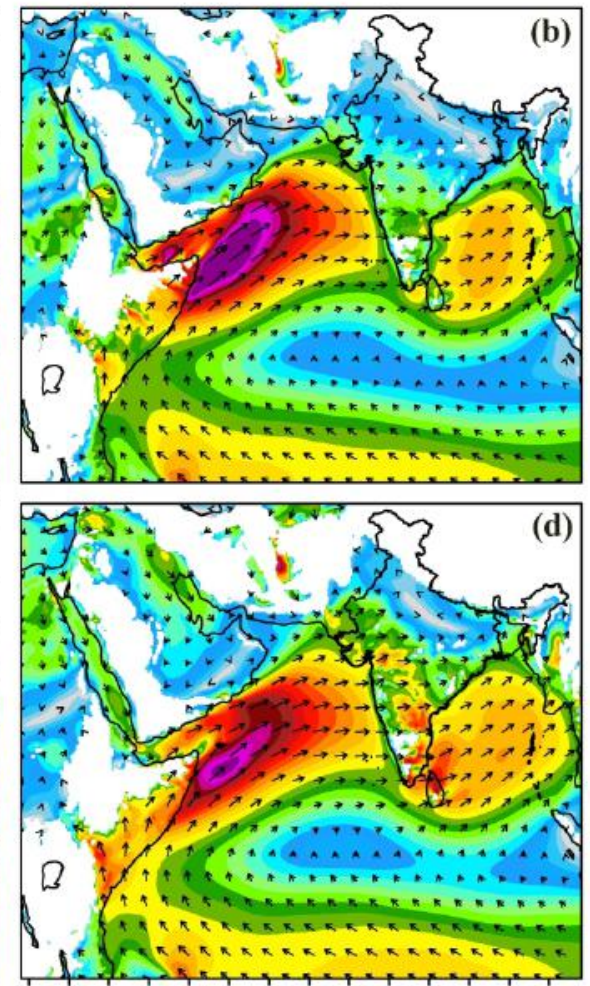

(d)

(b) 3OE 35E 4OE 45E 50E 55E 6OE 65E TOE 75E 8OE 85E 9OE 95

3OE 35E 40E 45E 50E 55E 6OE 65E 70E 75E BOE 85E 90E 95E

Figure 4. Spatial patterns of 6-hourly $925 \mathrm{hPa}$ winds at (a) 0000 UTC, (b) 0600 UTC, (c) 1200 UTC, and (d) 1800 UTC averaged for JJAS months of 37-years.

$267 \times 220 \mathrm{~mm}(300 \times 300 \mathrm{DPI})$ 


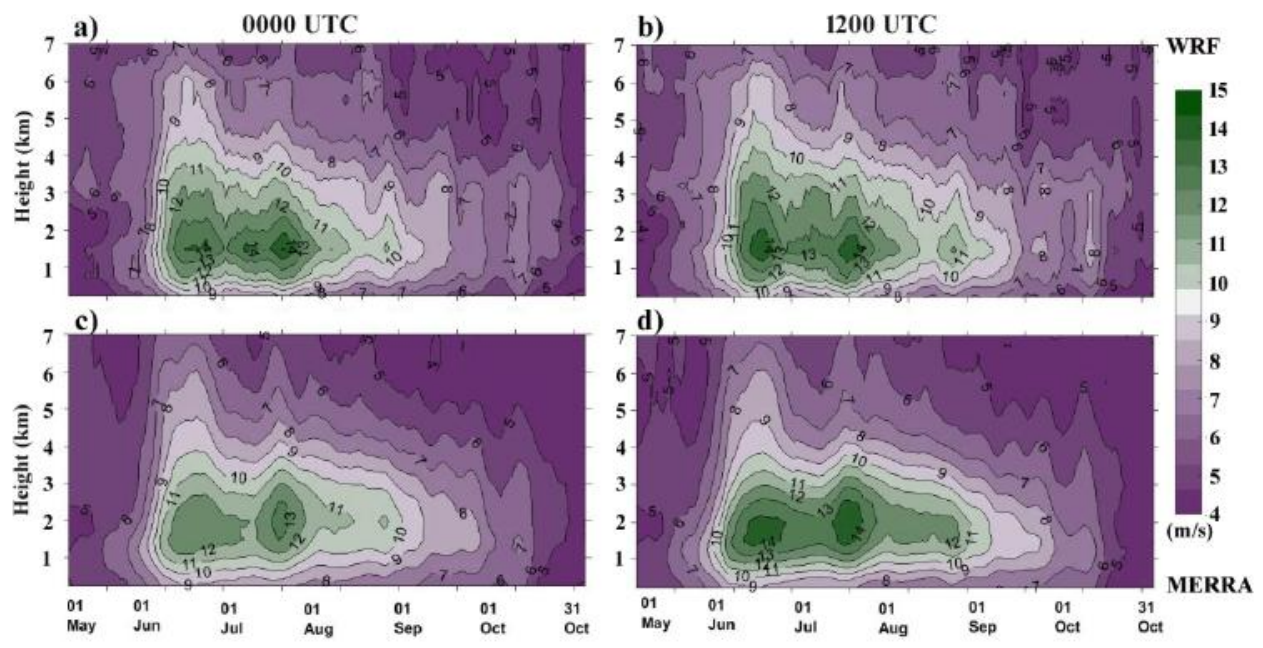

Figure 5. Time-height sections of 37-year mean winds at (a, c) 0000 UTC, and (b, d) 1200 UTC from WRF (top panels) and radiosonde (bottom panels) plotted at Minicoy.

$635 \times 318 \mathrm{~mm}(72 \times 72 \mathrm{DPI})$ 

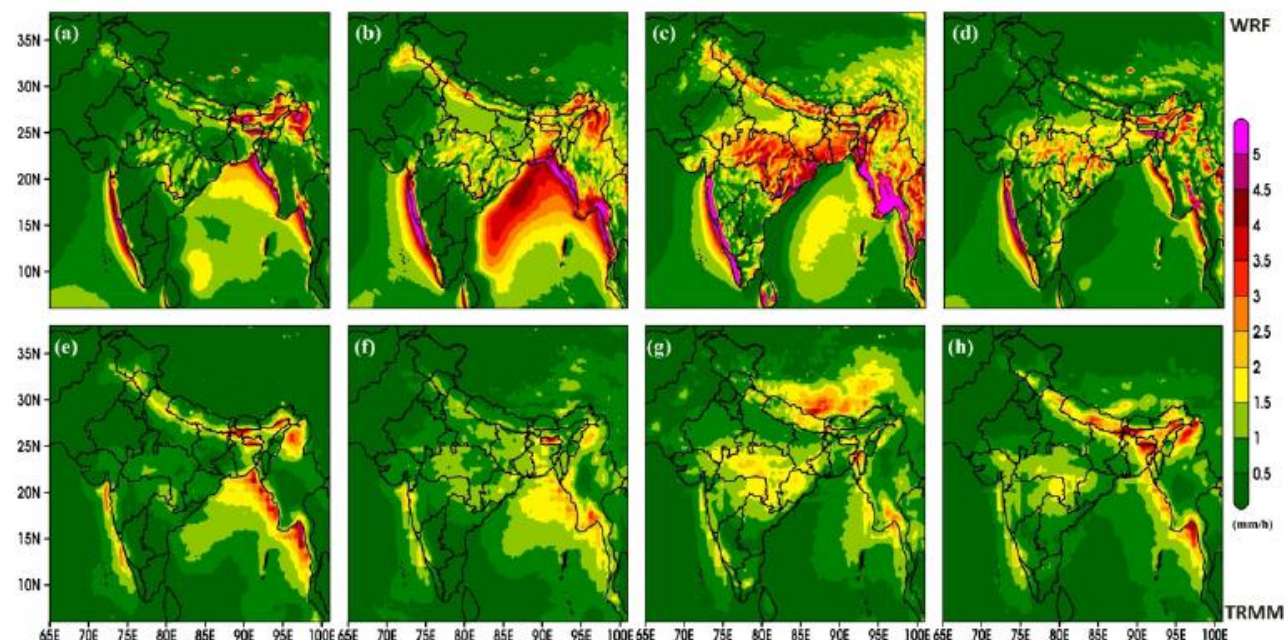

Figure 6. Spatial distribution of 6-hourly rainfall $(\mathrm{mm} / \mathrm{h})$ at (a, b) 0000 UTC, $(\mathrm{c}, \mathrm{d}) 0600 \mathrm{UTC},(\mathrm{e}, \mathrm{f}) 1200$ UTC, and $(g, h) 1800$ UTC from WRF (top panels) and TRMM (bottom panels).

$277 \times 140 \mathrm{~mm}(300 \times 300 \mathrm{DPI})$ 

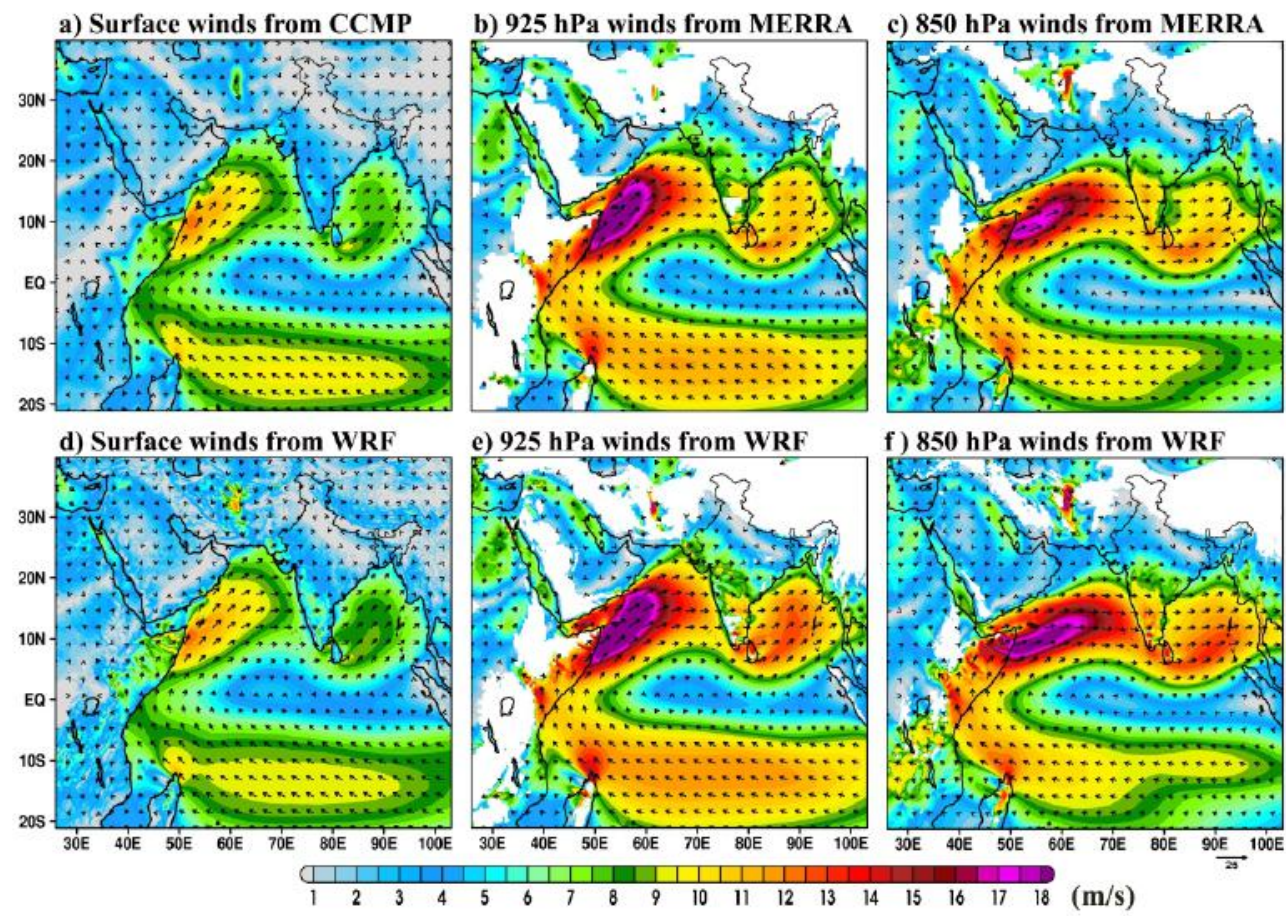

e) $925 \mathrm{hPa}$ winds from WRF

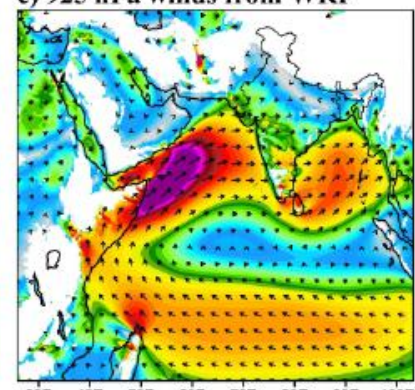

f) $850 \mathrm{hPa}$ winds from WRF

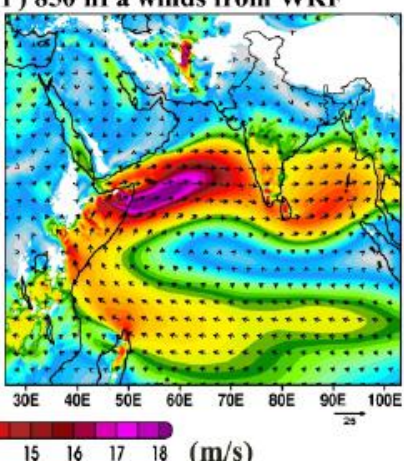

Figure 7. 37-year mean JJAS winds plotted for surface (a, d), $925 \mathrm{hPa}(\mathrm{b}, \mathrm{e})$ and $850 \mathrm{hPa}(\mathrm{c}, \mathrm{f})$ levels. Wind magnitude shown in shaded and direction as vector.

$2328 \times 1659 \mathrm{~mm}(72 \times 72 \mathrm{DPI})$ 
(a)Winds averaged over latitudes of $5-20^{\circ} \mathrm{N}$
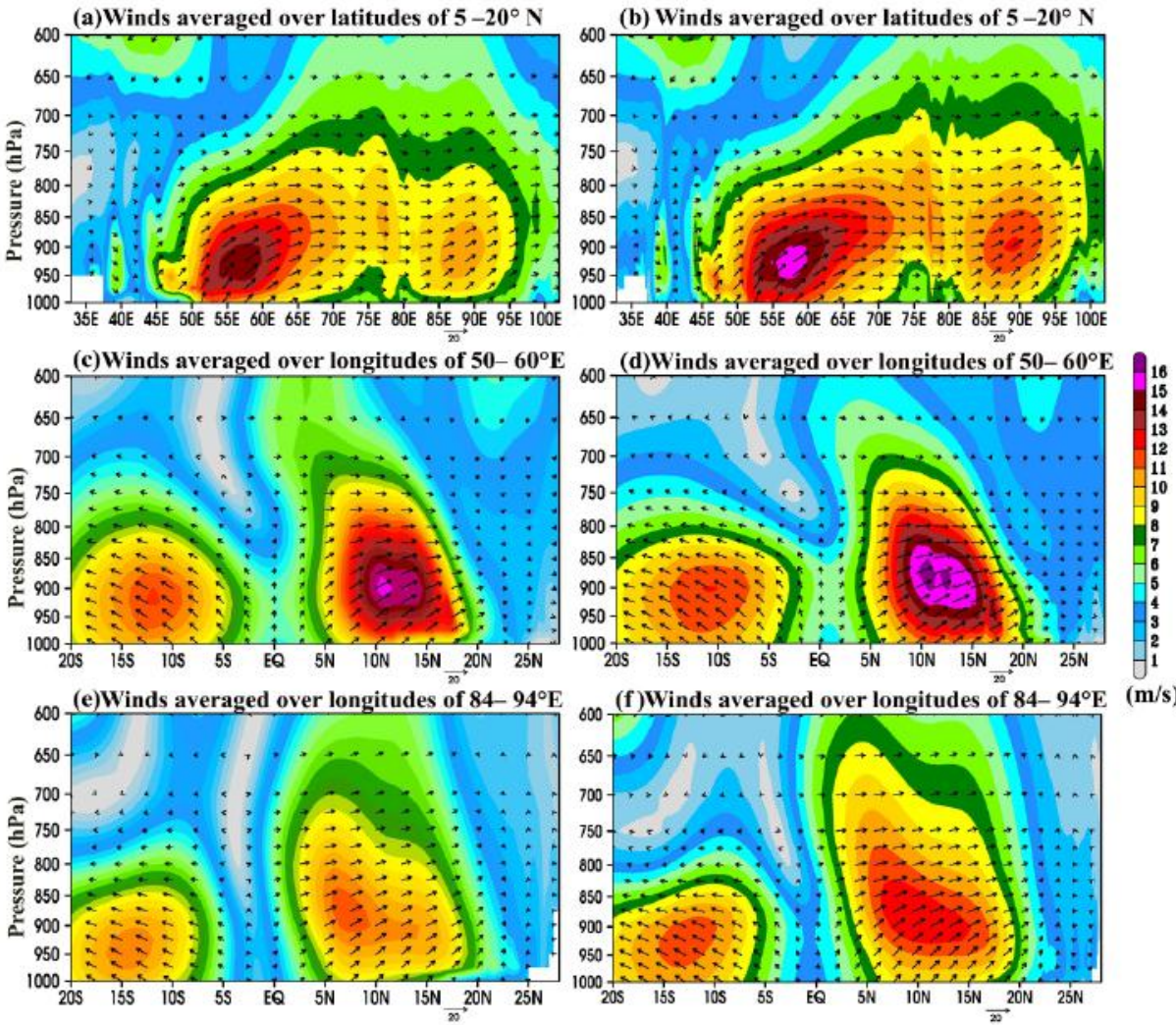

Figure 8. Pressure latitude and longitude sections of 37-year mean JJAS winds from MERRA2 (left panels) and WRF (right panels). Horizontal wind magnitude shown in shaded and direction as vector.

$2286 \times 1905 \mathrm{~mm}(72 \times 72$ DPI $)$ 

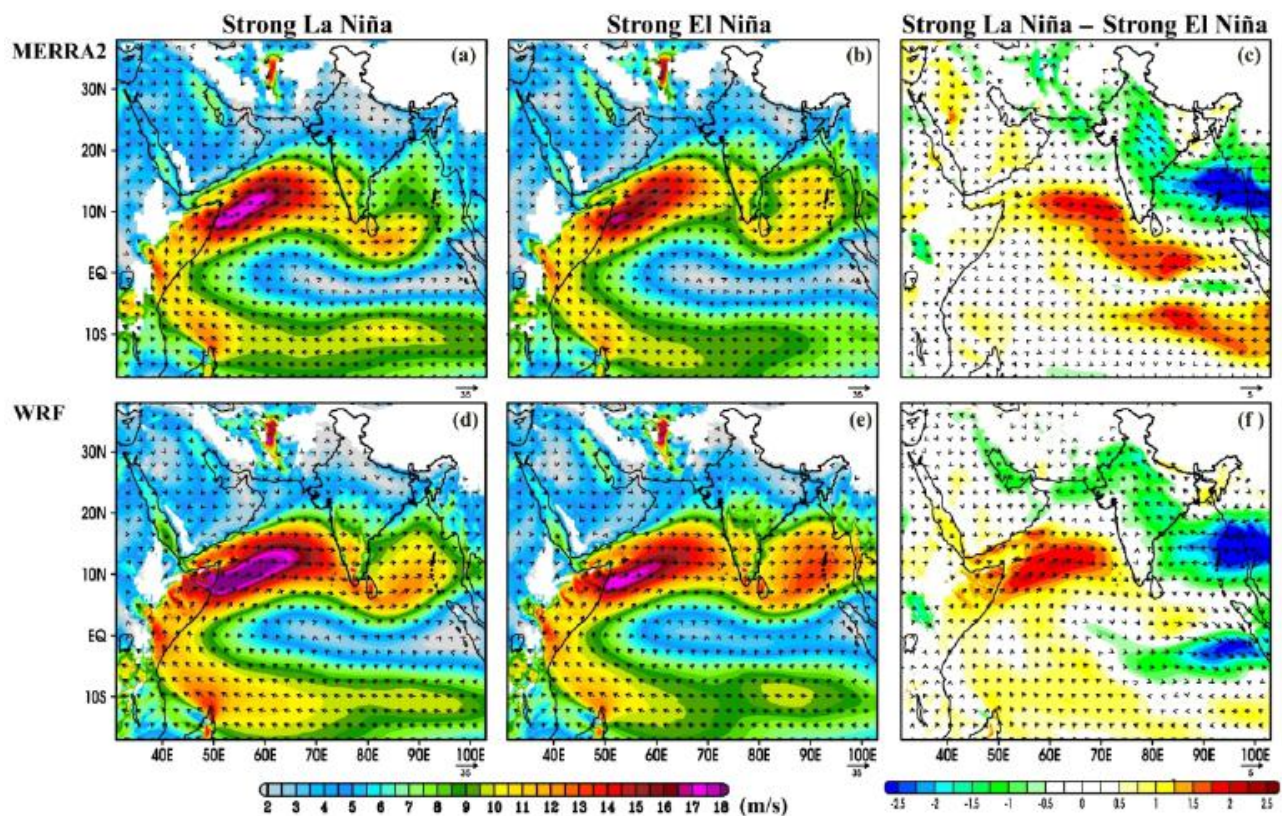

Figure 9. Composite of JJAS winds (at $850 \mathrm{hPa}$ ) plotted during (a, e) Strong La Niña years, (b,d) Strong El Niña years, and $(c, f)$ difference between La- Niña and El Niña years.

$192 \times 121 \mathrm{~mm}(300 \times 300 \mathrm{DPI})$ 

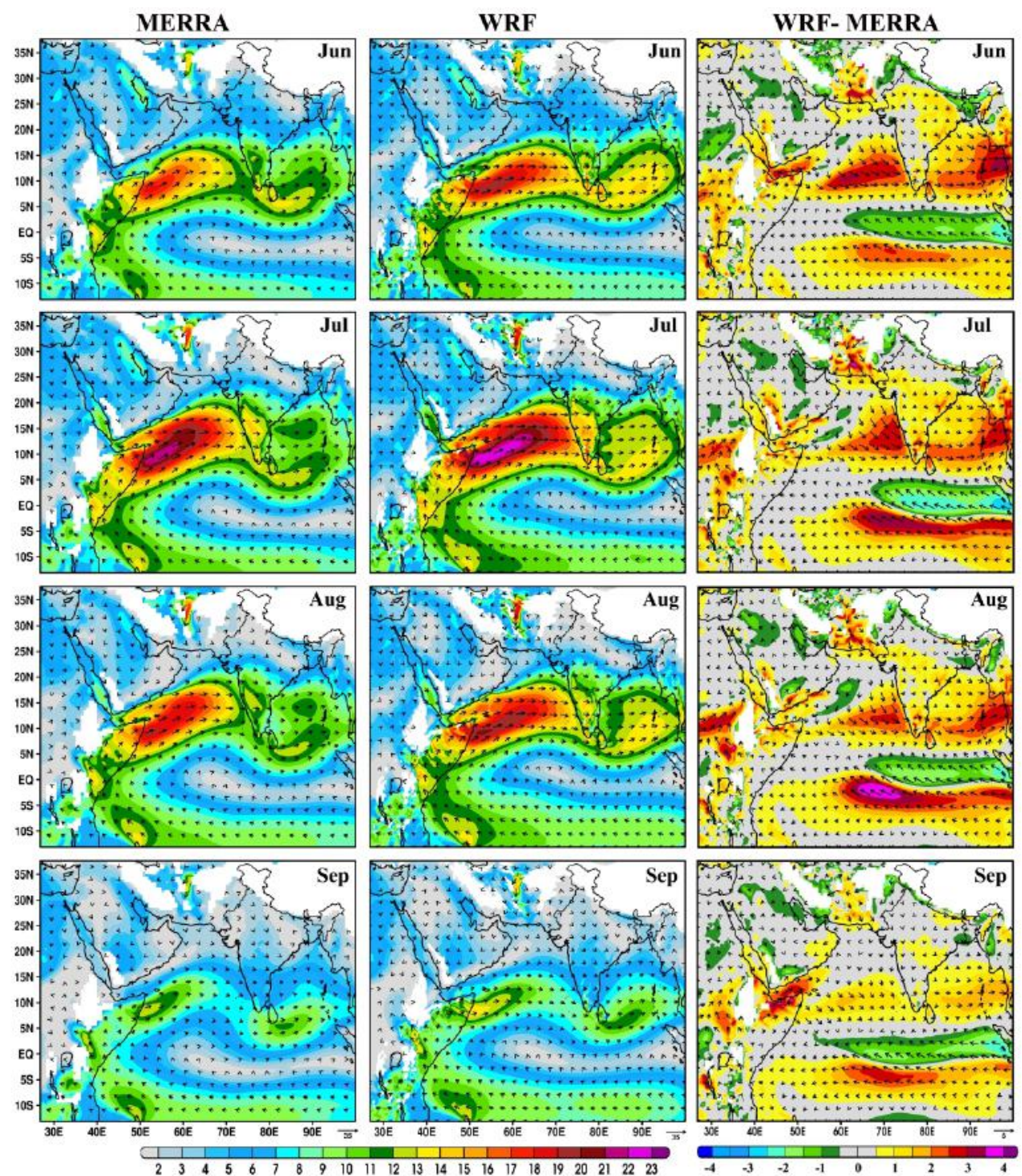

Figure 10. Spatial variation of 37-year mean monthly winds (at $850 \mathrm{hPa}$ ) from MERRA2 (right panels) WRF (middle panels) and the respective wind differences between WRF and MERRA (left panels).

$386 \times 437 \mathrm{~mm}(300 \times 300$ DPI $)$ 

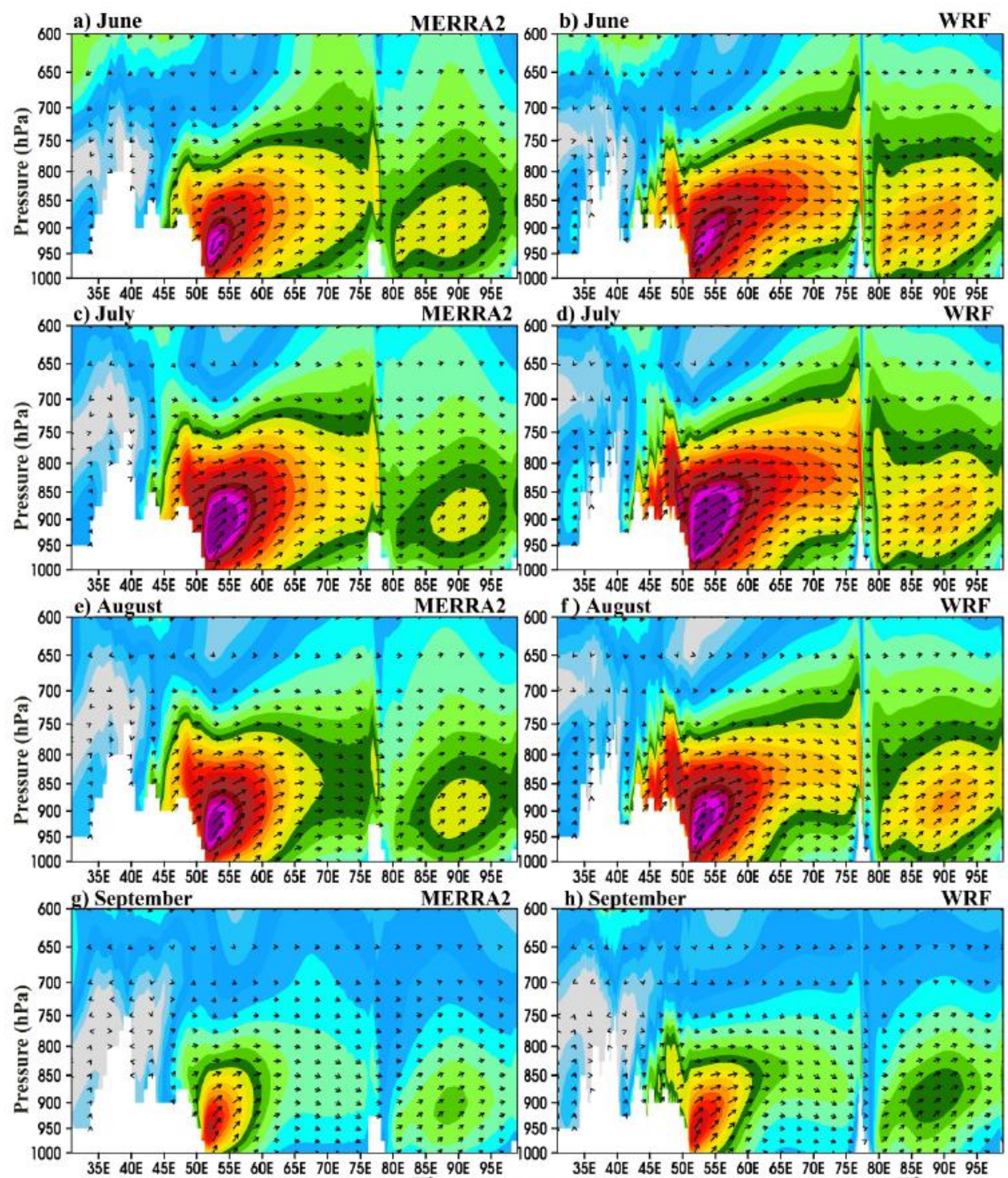

35E 40E 45E 50E 55E 60E 65E 70E 75E BOE 85E 90E 95E
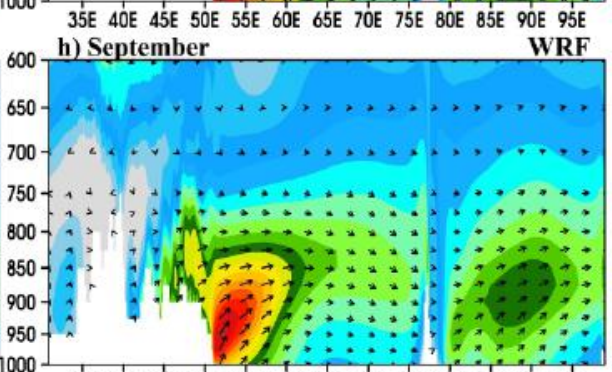

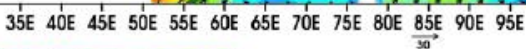

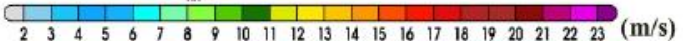

Figure 11. Longitude- pressure sections of 37-year mean monthly winds at latitude $\left(10^{\circ} \mathrm{N}\right)$ from $(\mathrm{a}, \mathrm{b}) \mathrm{June}$, (c, d) July, (e, f) August, and ( $g$, h) September. 

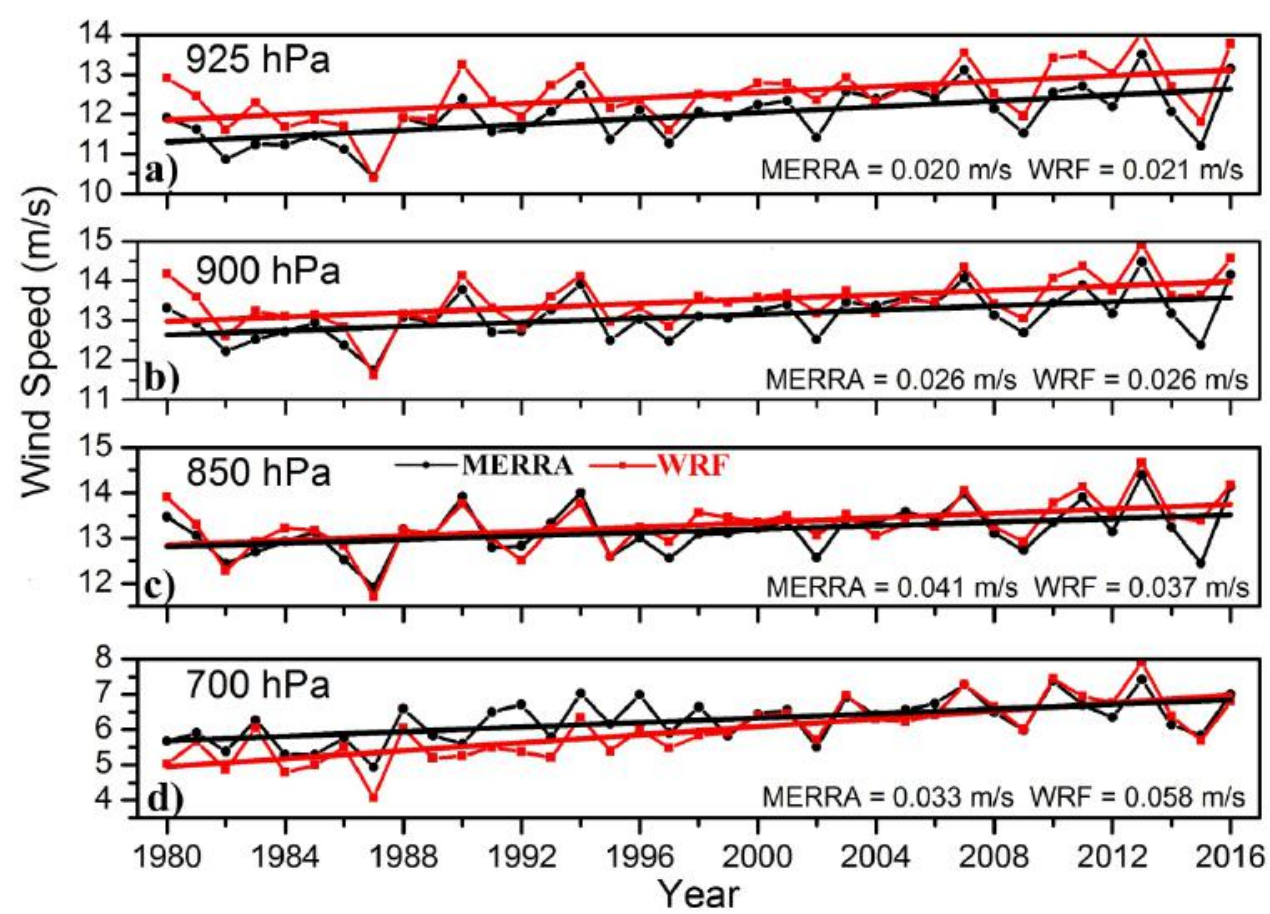

Figure 12. Time series of MERRA2 and WRF winds averaged over the core region of MLL] (i.e., $10^{\circ} \mathrm{N}-15^{\circ} \mathrm{N}$ and $50^{\circ} \mathrm{E}-60^{\circ} \mathrm{E}$ ) at (a) $925 \mathrm{hPa}$, (b) $900 \mathrm{hPa}$, (c) $850 \mathrm{hPa}$, and (d) $700 \mathrm{hPa}$ levels. 

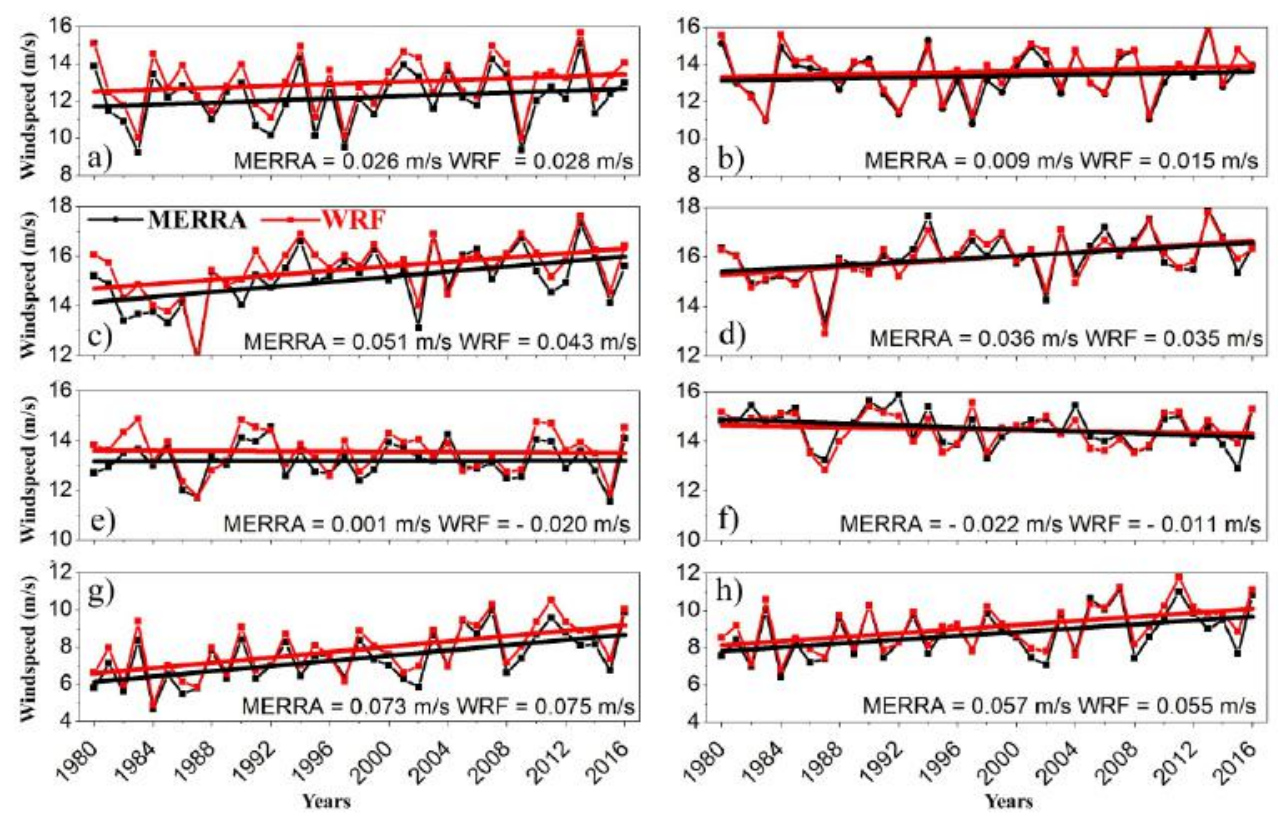

Figure 13. Time series of monthly mean $925 \mathrm{hPa}$ (left panels) and $850 \mathrm{hPa}$ (right panels) winds of MLLJ during ( $a, b)$ June; ( $c$, d) July; $(e, f)$ August; and $(g, h)$ September.

$289 \times 183 \mathrm{~mm}(300 \times 300 \mathrm{DPI})$ 


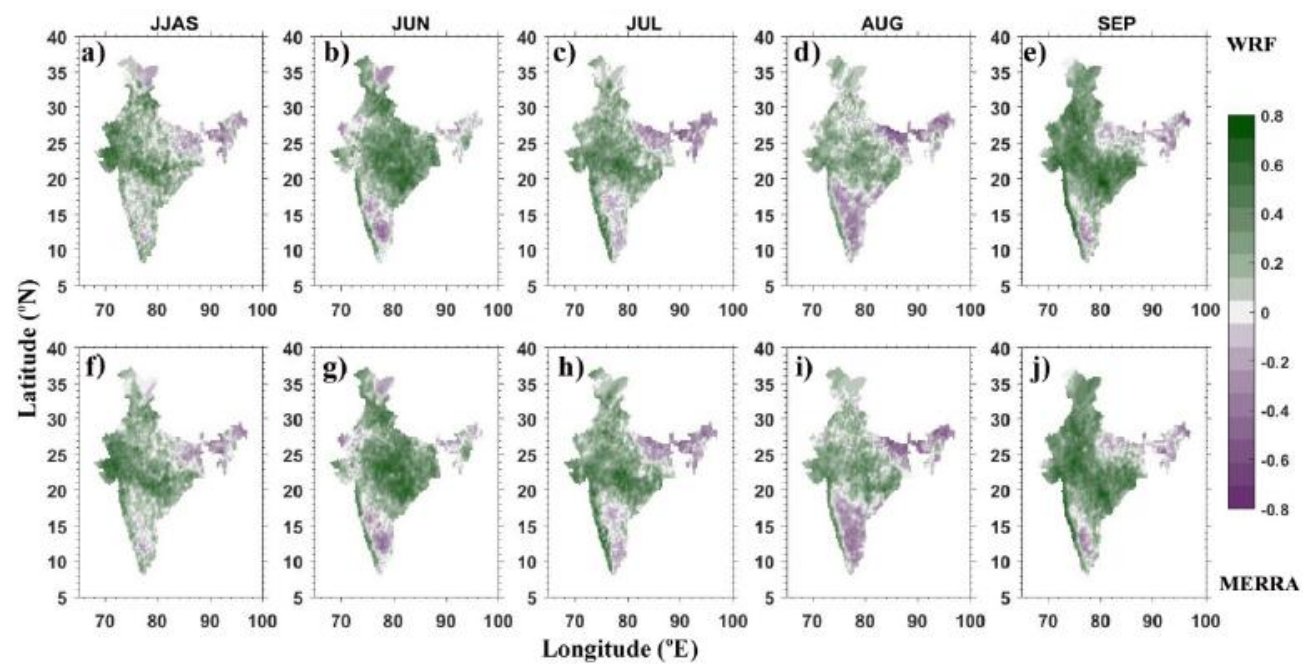

Figure 14. Spatial distributions of correlation coefficients computed using the strength of MLLJ (at $850 \mathrm{hPa}$ ) and the corresponding observed ISMR.

$642 \times 325 \mathrm{~mm}(72 \times 72 \mathrm{DPI})$ 


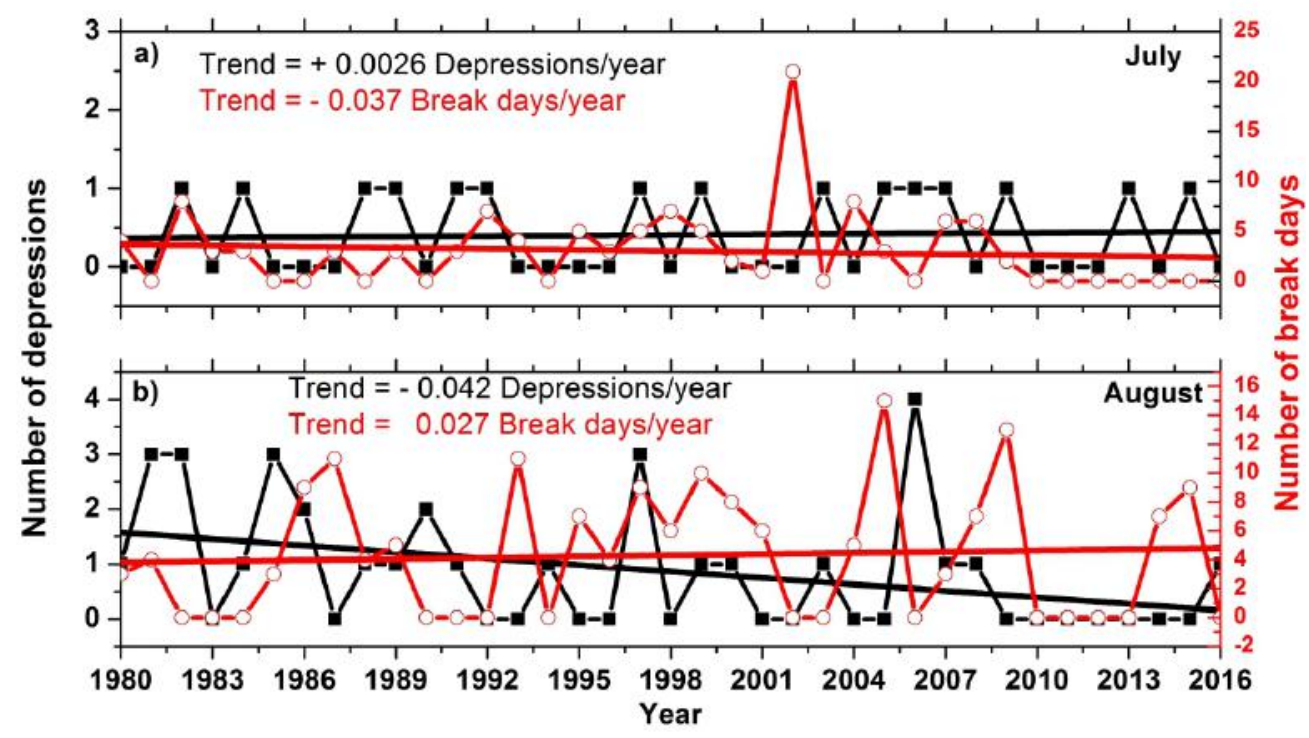

Figure 15. Variations in the number of depressions over Bay of Bengal and number of days associated with break conditions during 1980-2016 July and August months.

$428 \times 242 \mathrm{~mm}(300 \times 300 \mathrm{DPI})$ 

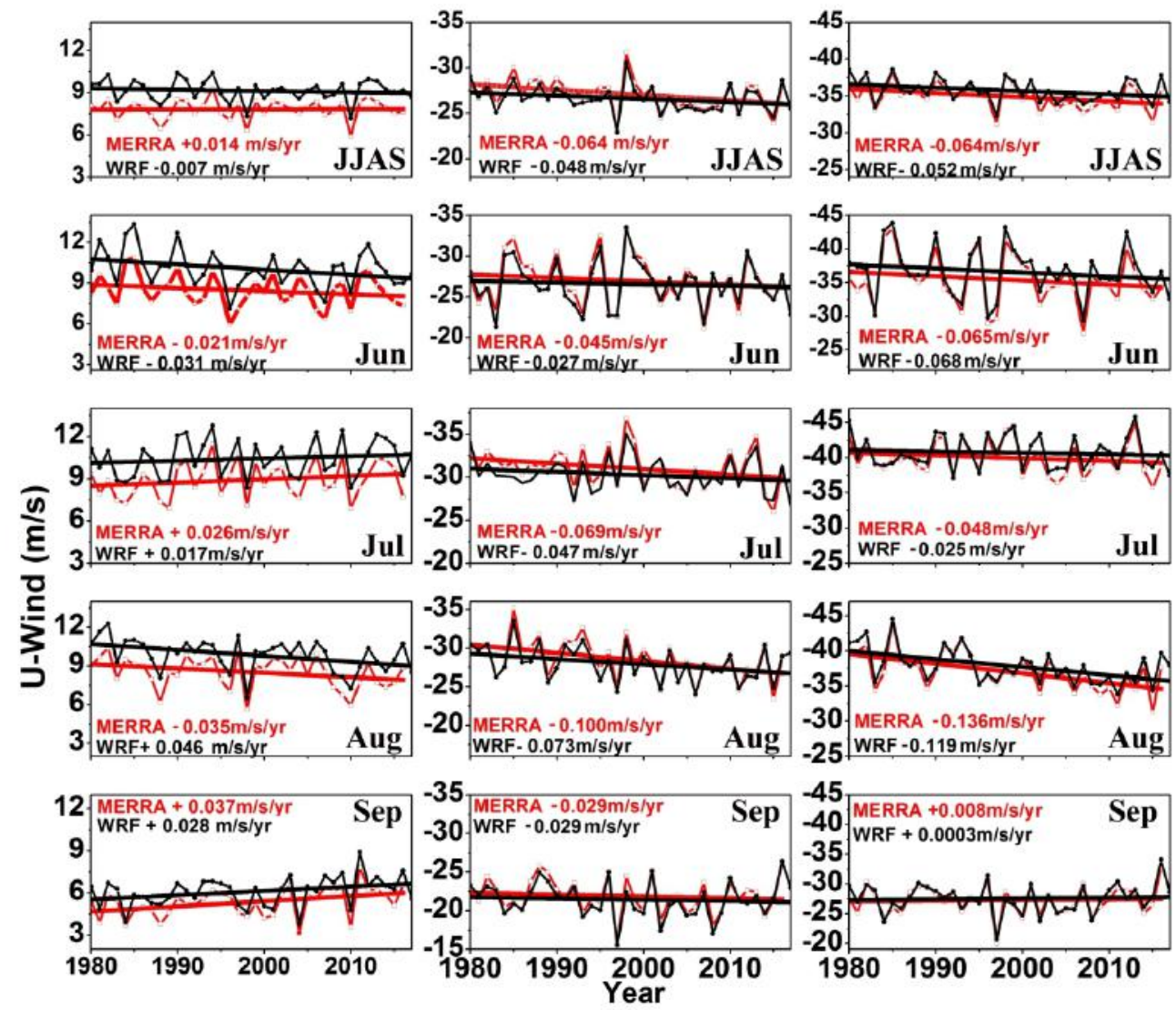

Figure 16. Variation of zonal wind $(\mathrm{m} / \mathrm{s})$ during the entire ISM season and for individual months at $850 \mathrm{hPa}$ (left panels), at $100 \mathrm{hPa}$,(middle panels) and vertical zonal wind shear (in m/s) between $850 \mathrm{hPa}$ and 100 hPa levels (left panels).

$222 \times 192 \mathrm{~mm}(300 \times 300 \mathrm{DPI})$ 

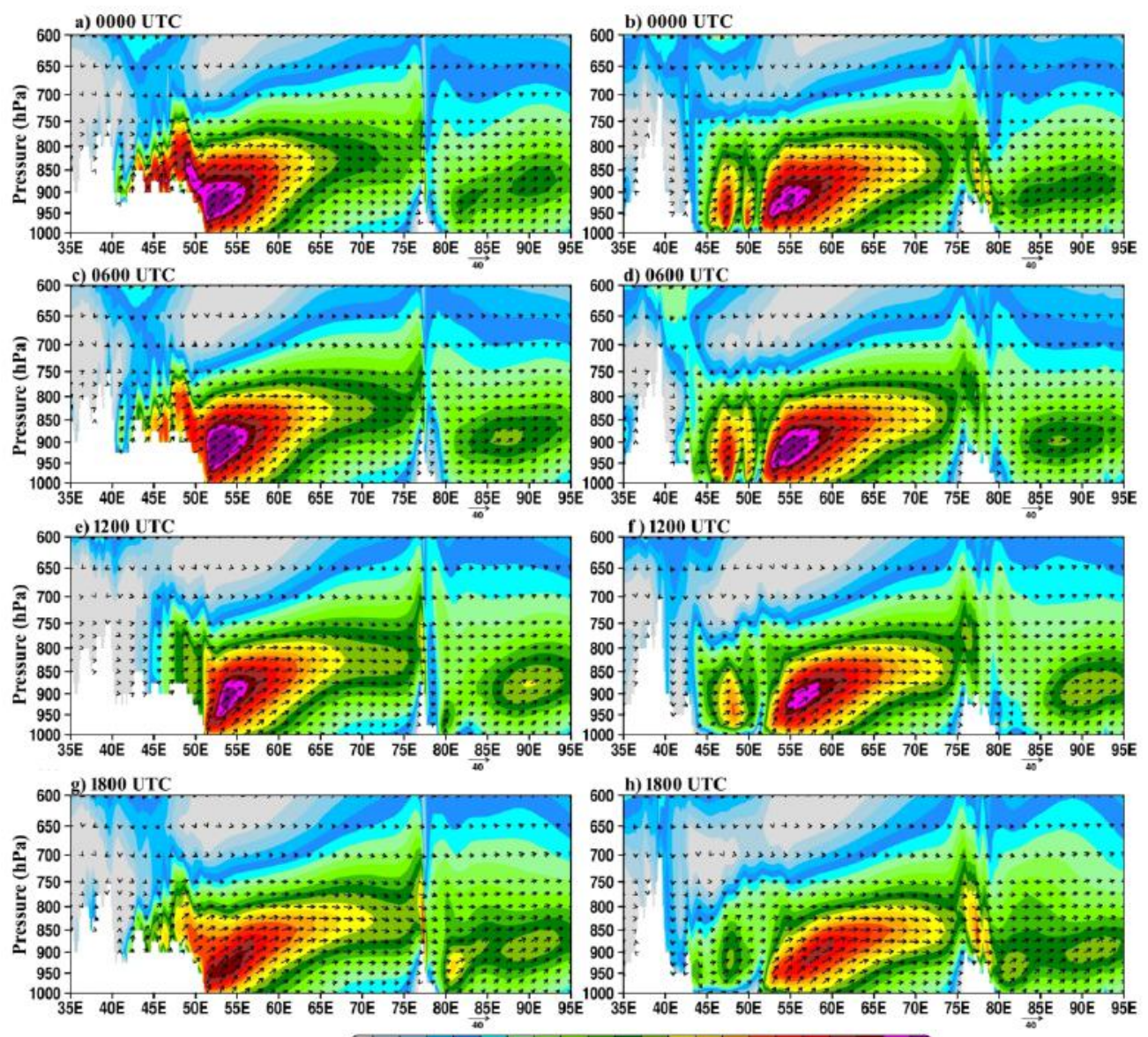

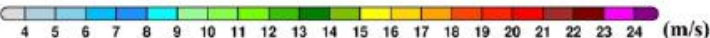

Figure S1. Longitudinal pressure-sections of mean JJAS winds at latitude $10^{\circ} \mathrm{N}$ (left panel) and $13^{\circ} \mathrm{N}$ (right panel) at $0000 \mathrm{UTC}(\mathrm{a}, \mathrm{b}) ; 0600 \mathrm{UTC}(\mathrm{c}, \mathrm{d}) ; 1200 \mathrm{UTC}(\mathrm{e}, \mathrm{f})$ and 1800 UTC (g, h).

$216 \times 216 \mathrm{~mm}(300 \times 300 \mathrm{DPI})$ 


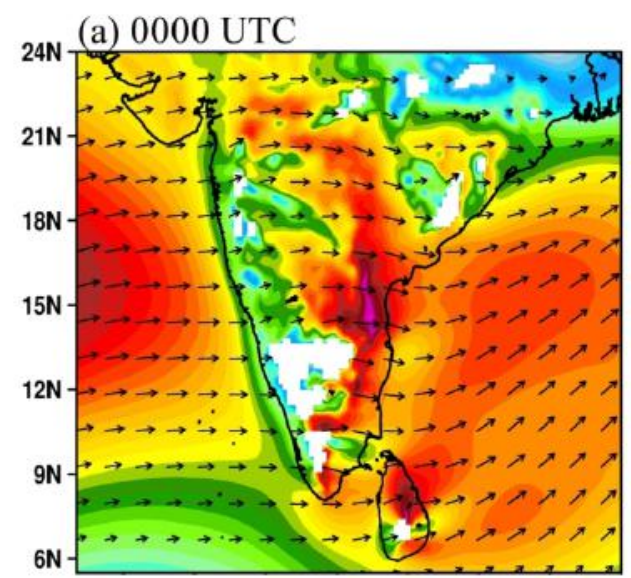

(b) 0600 UTC
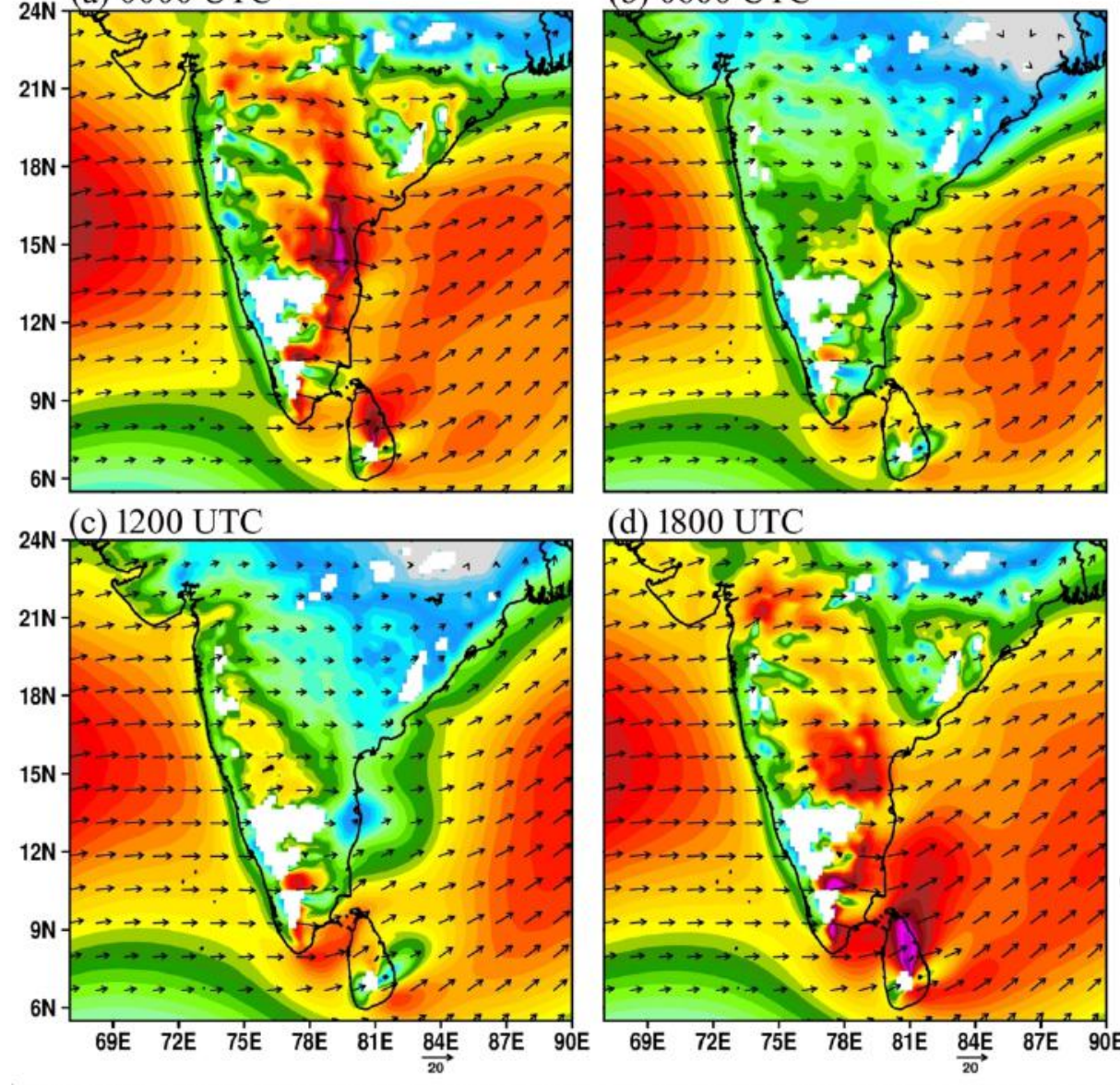

(d) 1800 UTC

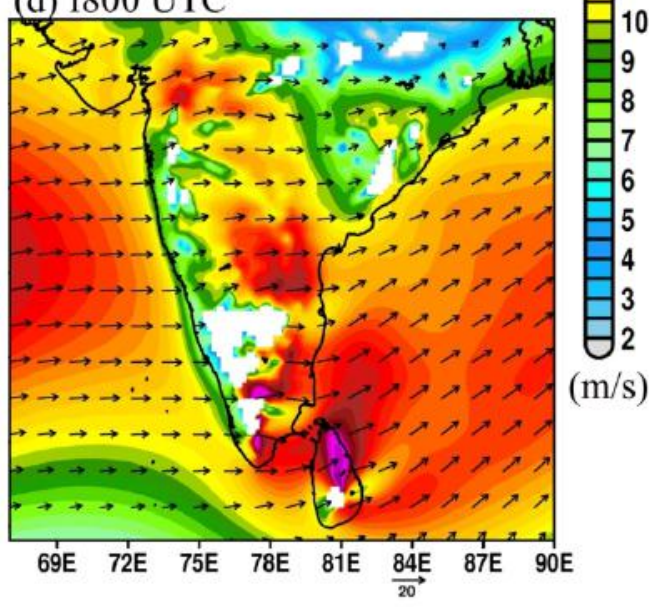

Figure S2. Spatial patterns of 6-hourly winds $(925 \mathrm{hPa})$ over Indian Peninsular.

$172 \times 168 \mathrm{~mm}(300 \times 300 \mathrm{DPI})$ 

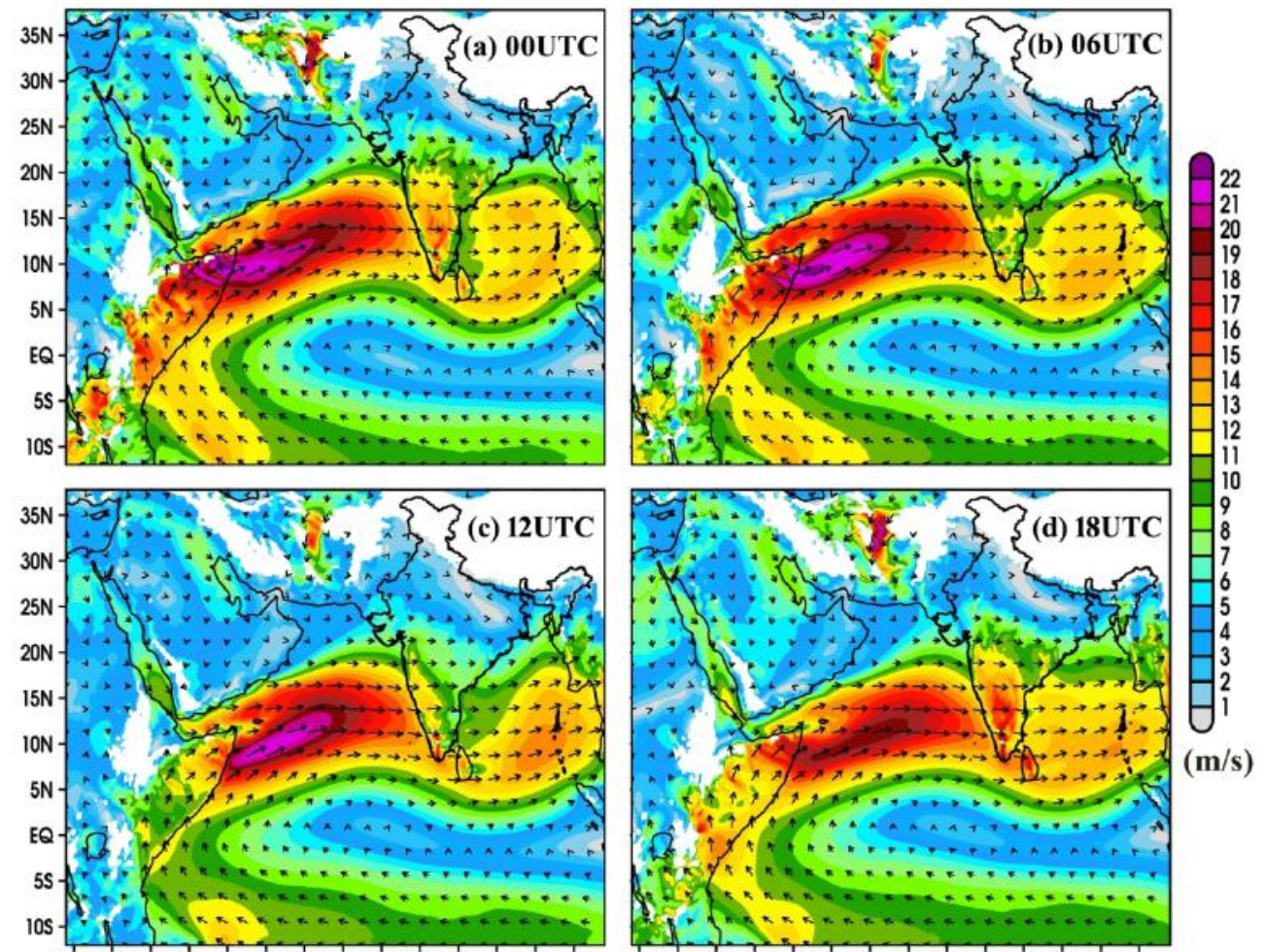

30E 35E 40E 45E 50E 55E 60E 65E 70E 75E 80E 85E 90E 95E 30E 35E 40E 45E 50E 55E 60E 65E 70E 75E 80E 85E 90E 95E

Figure S3. Same as Figure $4 \stackrel{\mathrm{but}}{\mathrm{b}}$ plotted at $850 \mathrm{hPa}$ level

$187 \times 159 \mathrm{~mm}(300 \times 300 \mathrm{DPI})$ 

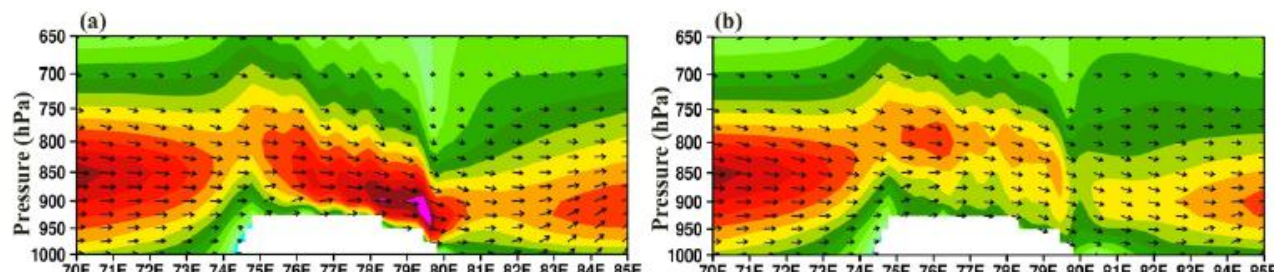

(c) T2E T3E 74E 75E 76E T7E 78E $79 E$ BOE 81E
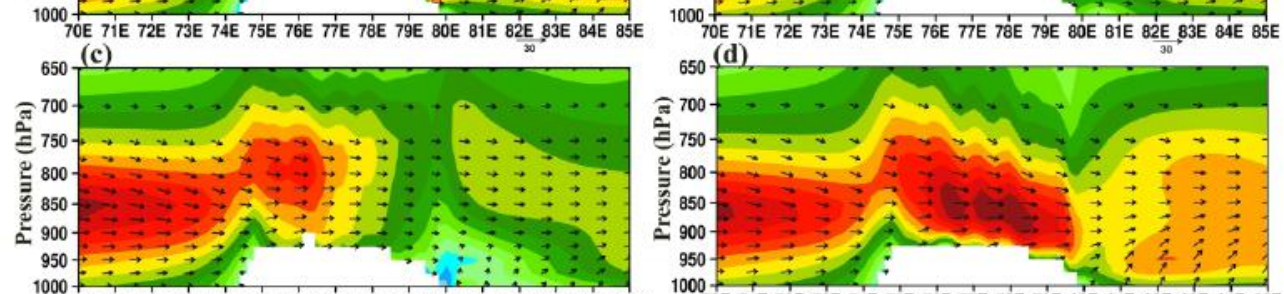
650 (d)

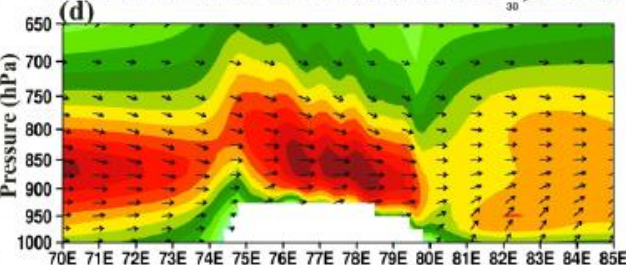
$70 \mathrm{E}$

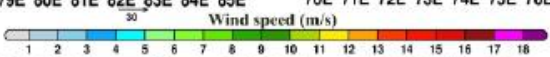

Figure S4. Longitudinal height-section of JJAS winds $(\mathrm{m} / \mathrm{s})$ plotted at latitude $20^{\circ} \mathrm{N}$ at (a) 0000 UTC, (b) 0600 UTC, (c) 1200 UTC, and (d) 1800 UTC.

$317 \times 170 \mathrm{~mm}(300 \times 300 \mathrm{DPI})$ 


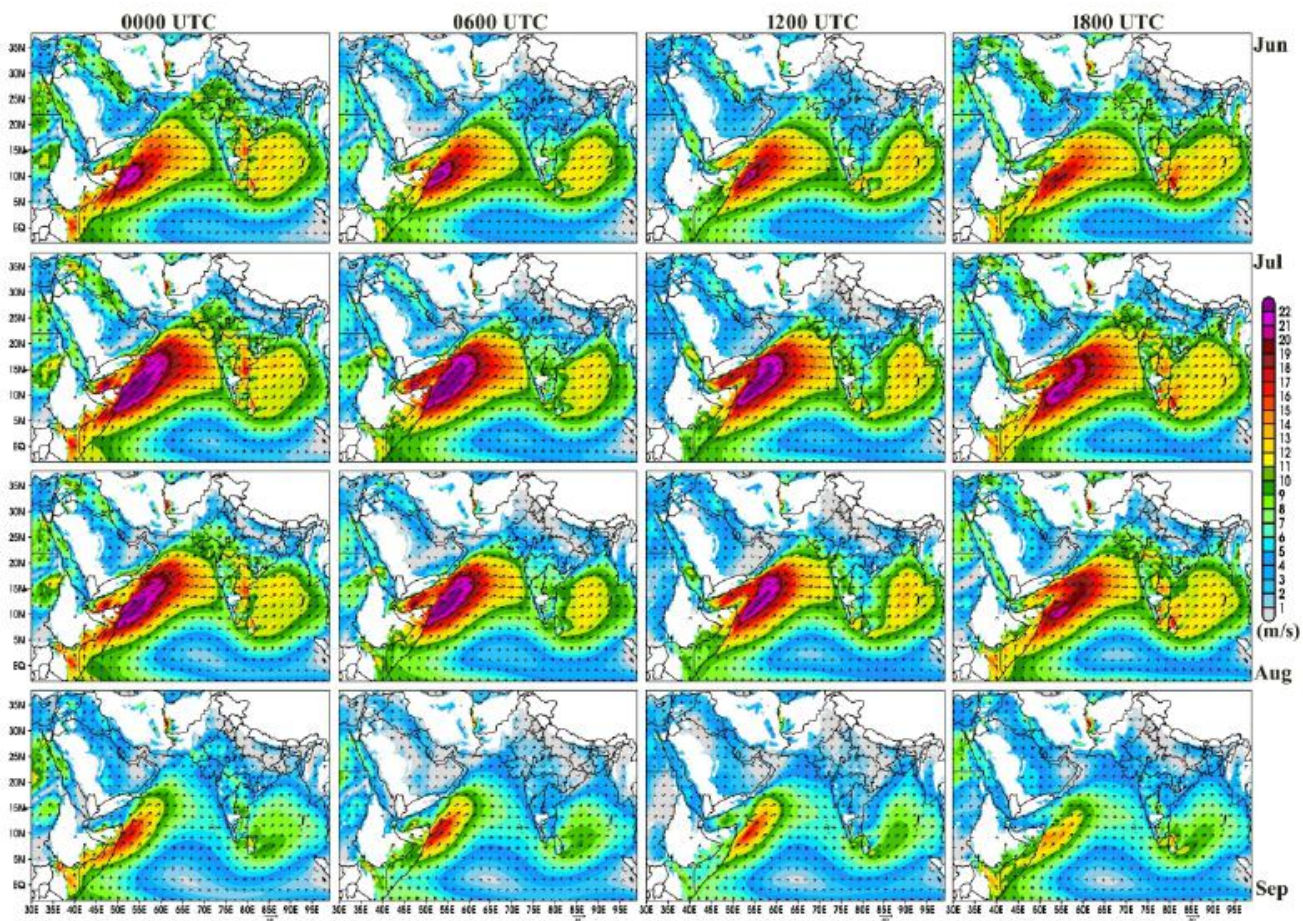

Figure S5. Spatial distribution of 6-hourly monthly winds from June to September.

$338 \times 251 \mathrm{~mm}(300 \times 300 \mathrm{DPI})$ 

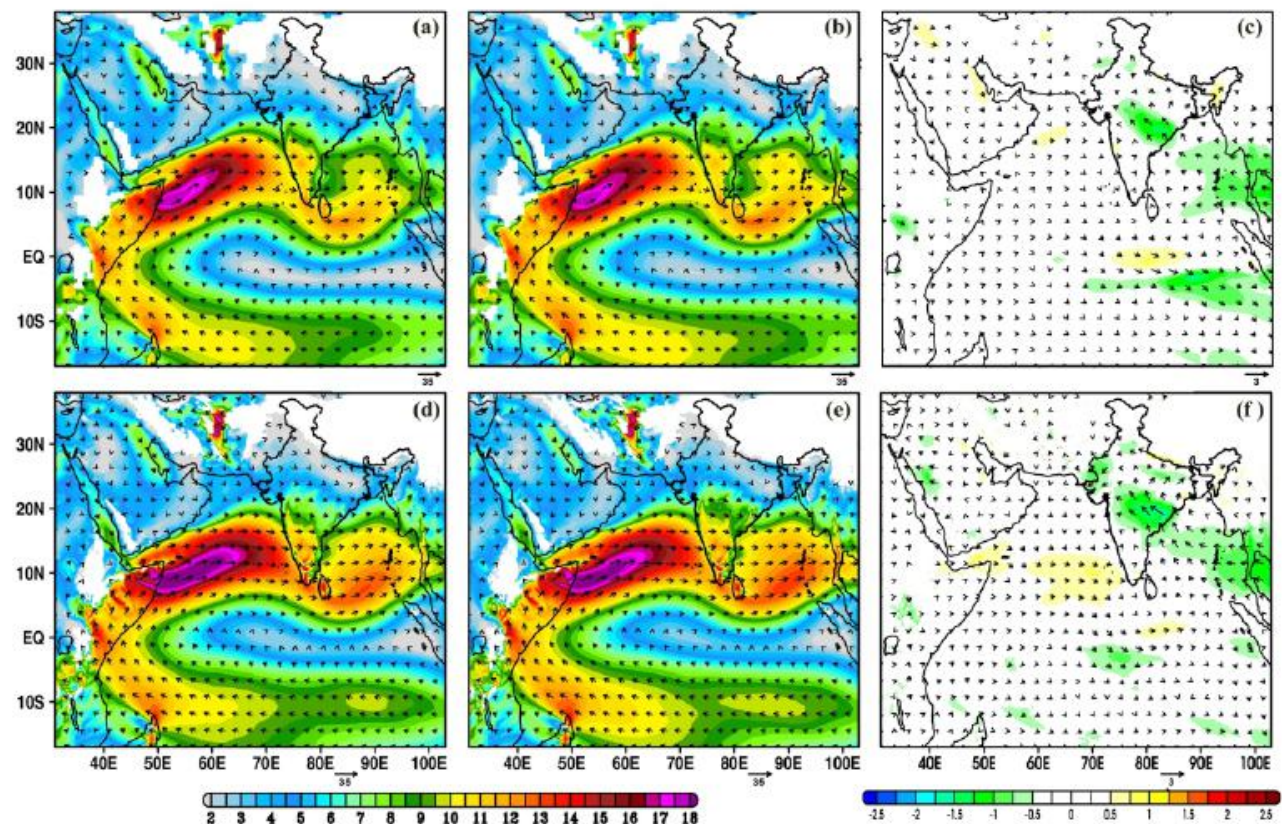

Figure S6. Composite of JJAS winds (at $850 \mathrm{hPa}$ ) plotted during (a, e) Moderate to week La Niña years, (b,d) Moderate to week EI Niña years, and (c, f) difference between the moderate to week La- Niña and EI Niña years.

$245 \times 183 \mathrm{~mm}(300 \times 300 \mathrm{DPI})$ 
(a) Strong La Niña

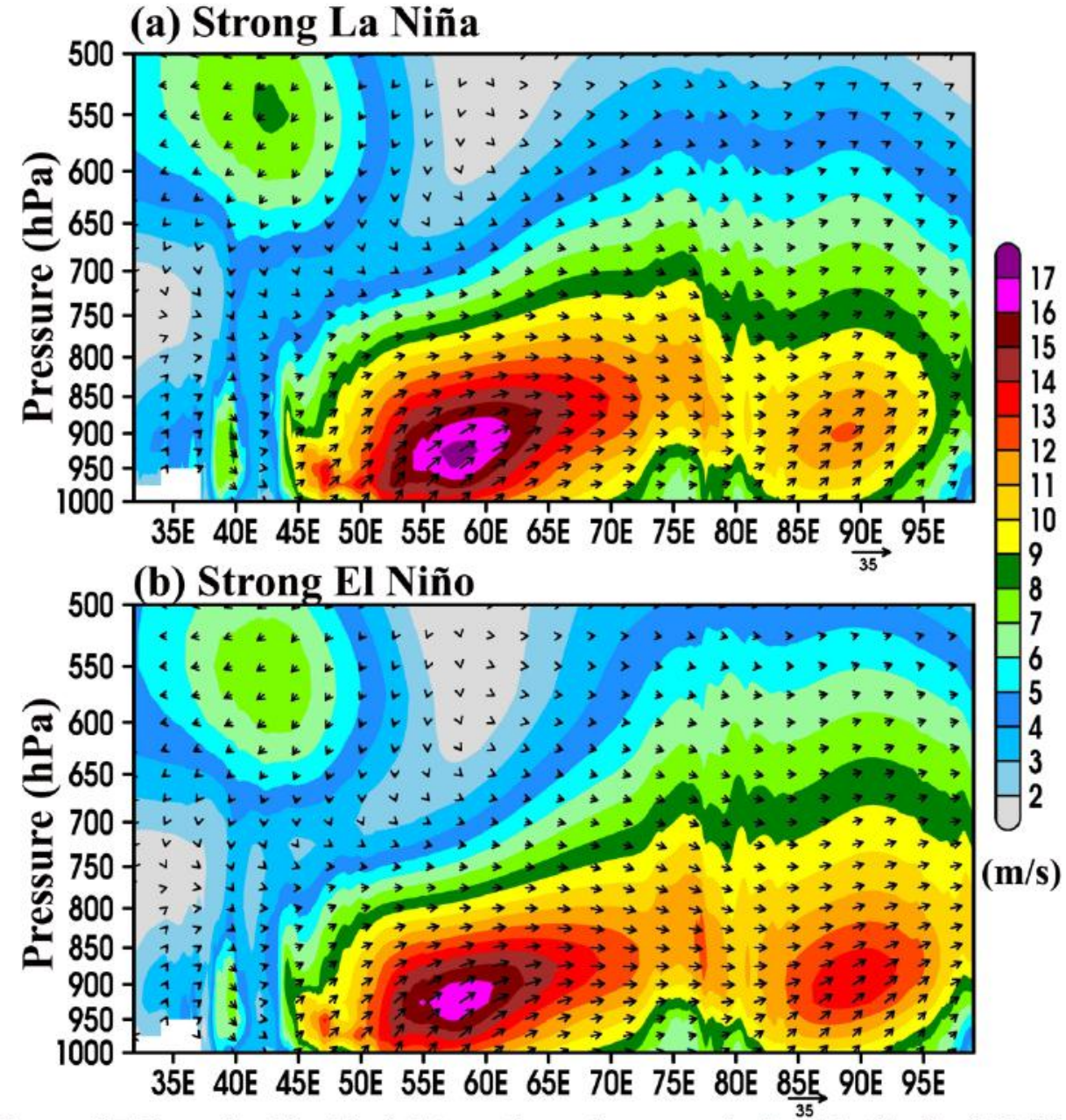

Figure S7. Longitudinal height-section of mean winds at latitude $\left(10^{\circ} \mathrm{N}\right)$ from June to September plotted during a) El- Niña and b) La- Niña years. 

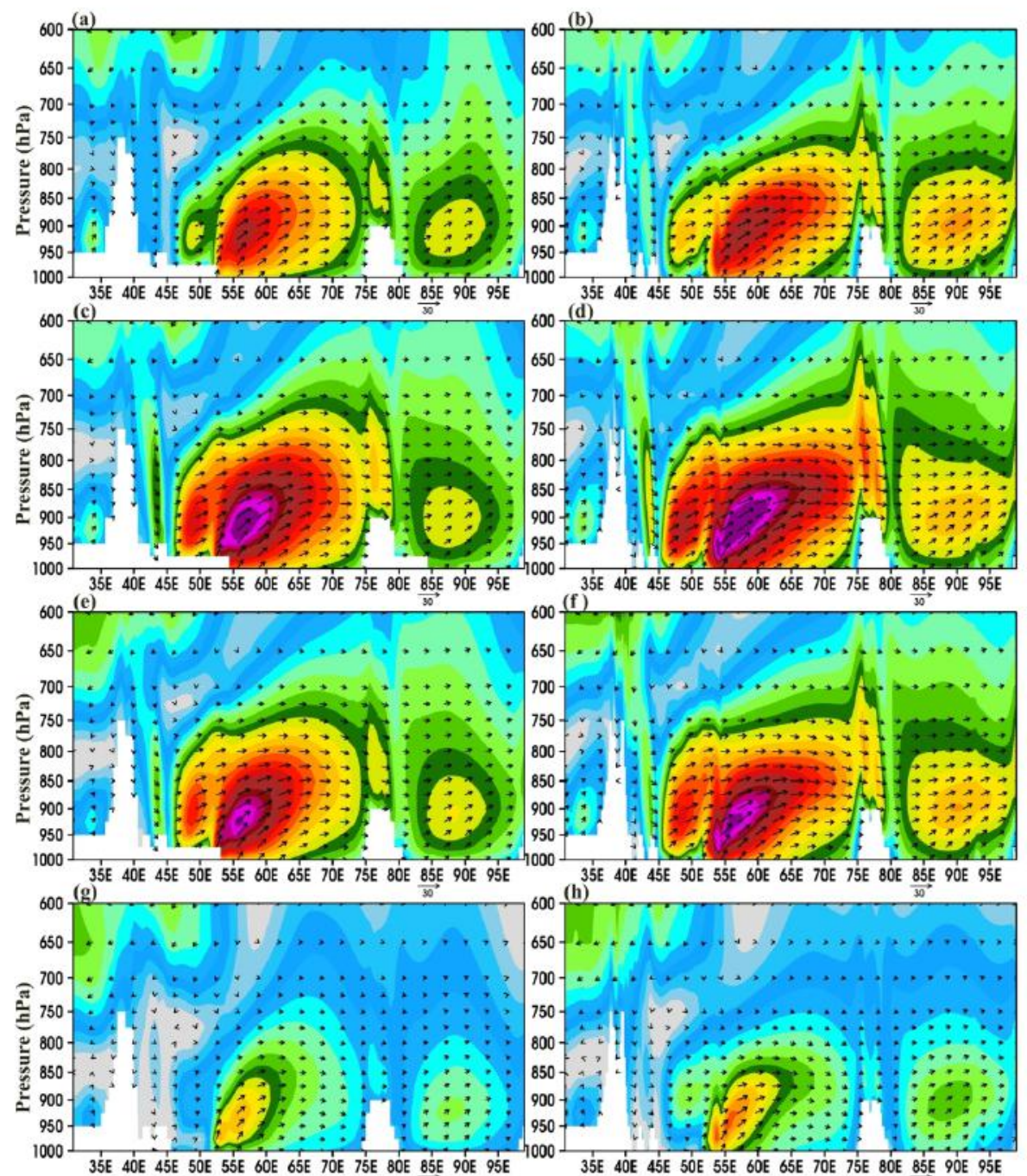

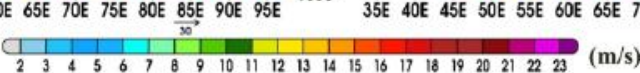

Figure S8. Longitudinal height-section of monthly mean winds at latitude $\left(13^{\circ} \mathrm{N}\right)$ from June to September.

$203 \times 256 \mathrm{~mm}(300 \times 300 \mathrm{DPI})$ 


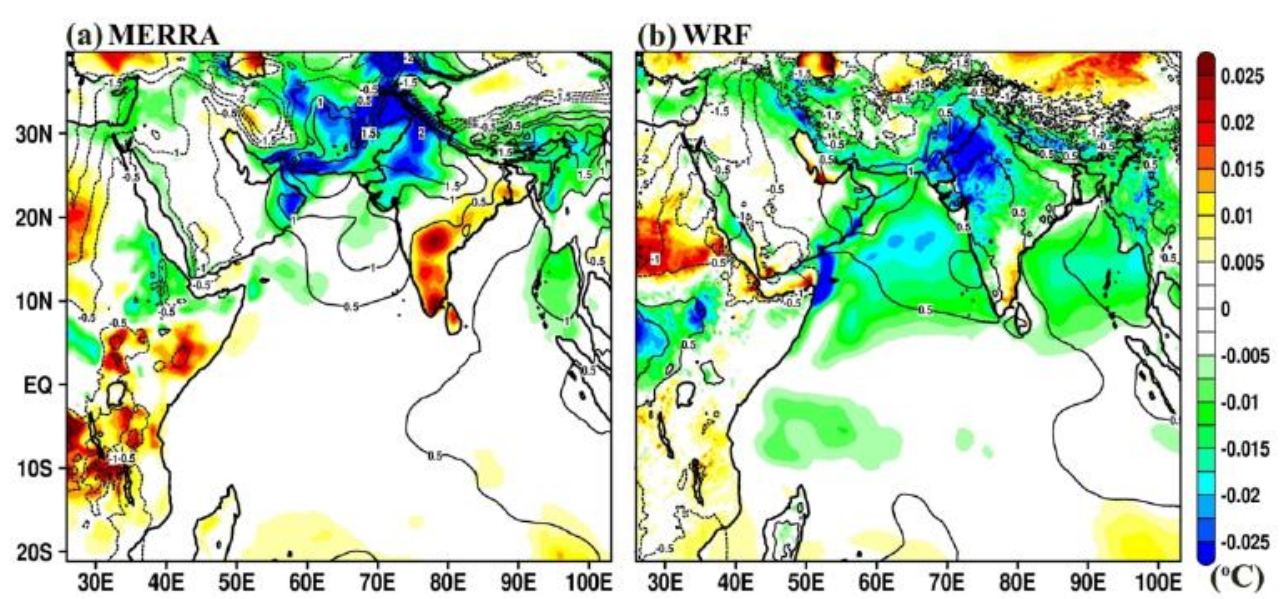

Figure S9. Spatial pattern of trends (1980-2016) in surface temperature (shown in shaded; ${ }^{\circ} \mathrm{C}$ ) and mean sea level pressure (shown in contour; $\mathbf{h P a}$ )

$177 \times 93 \mathrm{~mm}(300 \times 300 \mathrm{DPI})$ 
a)

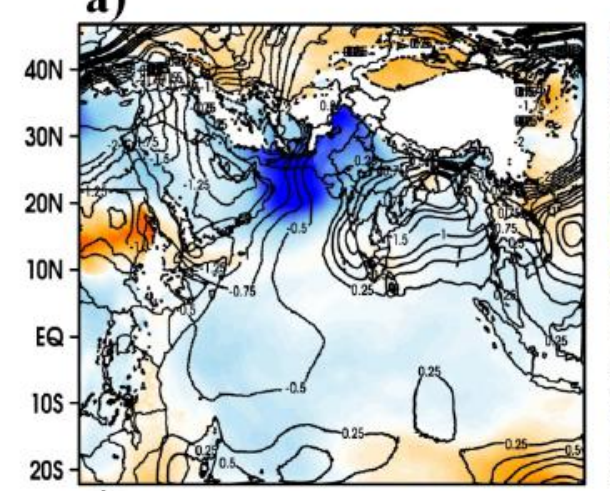

c)

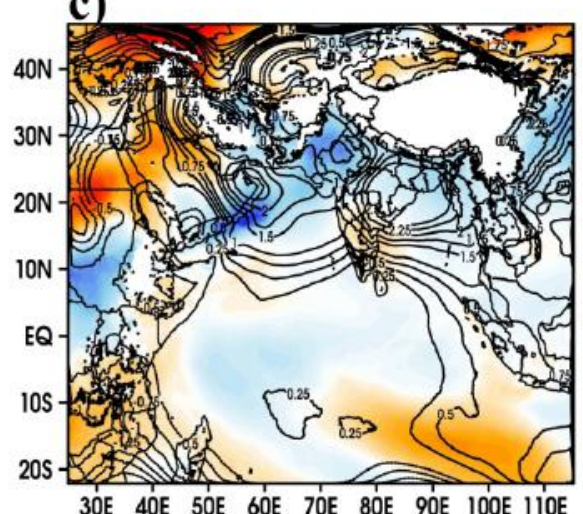

b)

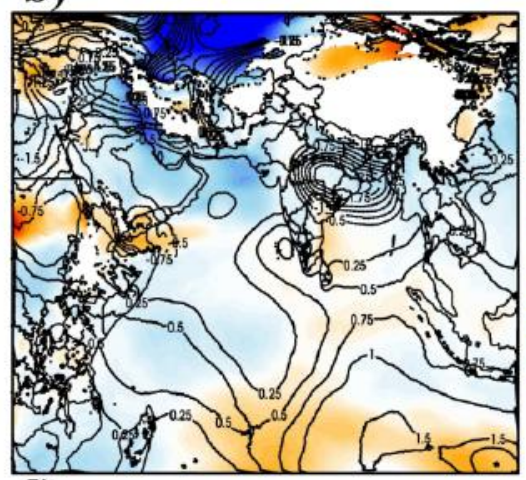

d)

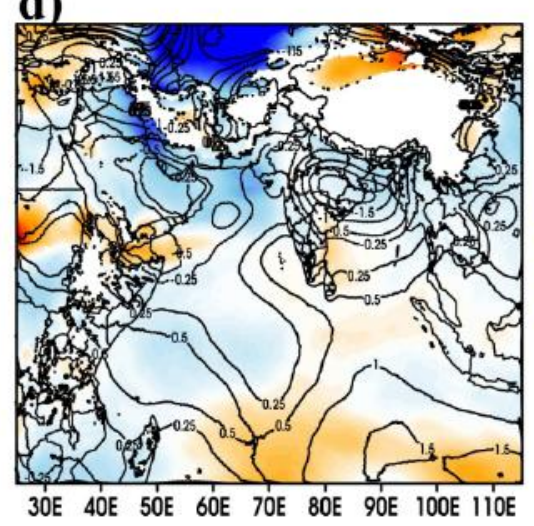

0.046 0.038 0.03 0.022 0.014 0.006 $-0.002$

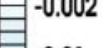

Figure S10. Analysis of trends in monthly mean temperature $\left({ }^{\circ} \mathrm{C} /\right.$ year) and geopotenital heights shown in contour (m/year) at 850-hPa during a) June, b) July, c) August and d) September. 